\title{
nawdex
}

NATIONAL WATER DATA EXCHANGE

DEFINITIONS OF DATABASE FILES AND FIELDS OF THE PERSONAL COMPUTER-BASED WATER DATA SOURCES DIRECTORY

U.S. Geological Survey

Open-File Report 91-184 


\section{Definitions of Database Files and Fields of the Personal Computer-Based Water Data Sources Directory}

\section{By J. Wayne Green}

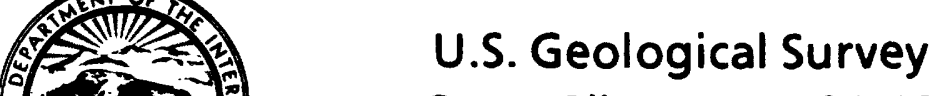

Open-File Report 91-184

(Supersedes Open-File Report 82-923) 


\section{U.S. DEPARTMENT OF THE INTERIOR MANUEL LUJAN, JR., SECRETARY \\ U.S. GEOLOGICAL SURVEY \\ DALLAS L. PECK, DIRECTOR}

For additional information write to:

Chief Hydrologist U.S. Geological Survey 421 National Center Reston, Virginia 22092
Copies of this report can be purchased from:

U.S. Geological Survey Books and Open-File Reports Section Box 25425, Federal Center Denver, Colorado 80225 


\section{CONTENTS}

Page

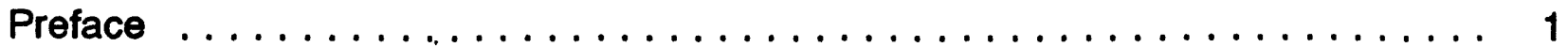

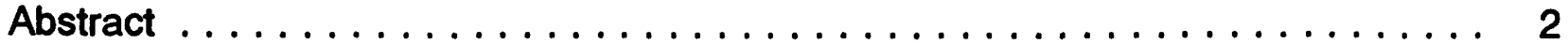

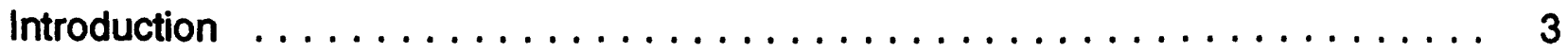

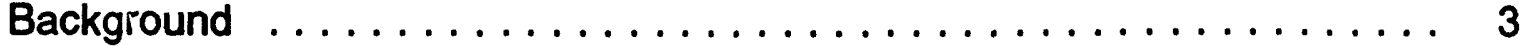

Purpose and scope ....................... 5

Overview of the Water Data Sources Directory ................. 6

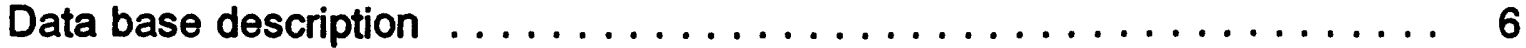

Data base structure ........................ 7

How to use this document . . . . . . . . . . . . . . . . . . . 7

Water Data Sources Directory (Personal Computer-Based System)

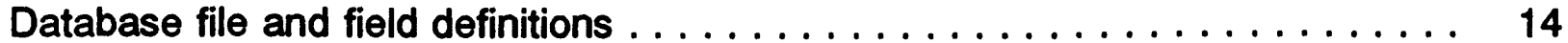

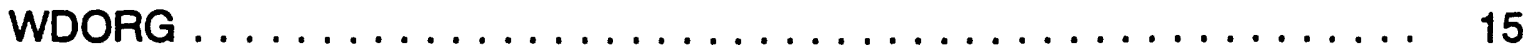

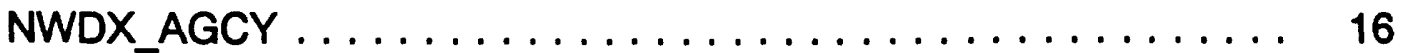

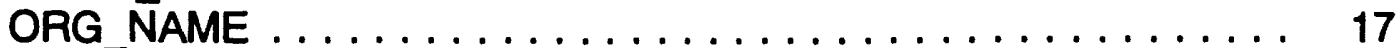

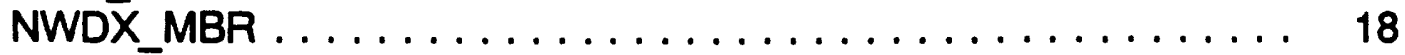

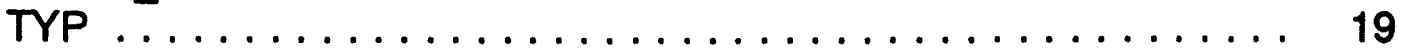

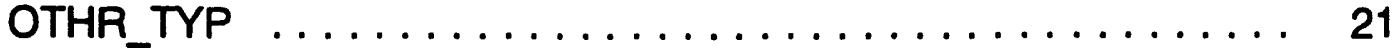

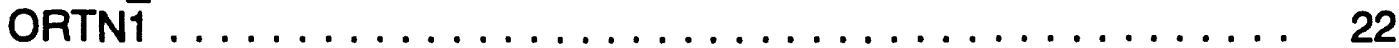

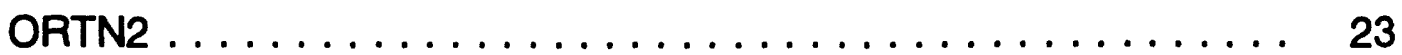

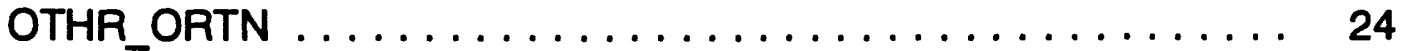

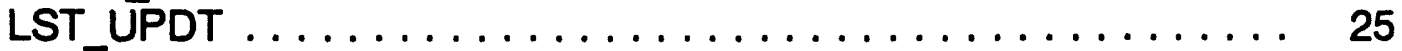

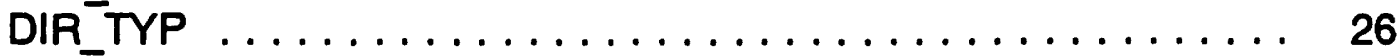

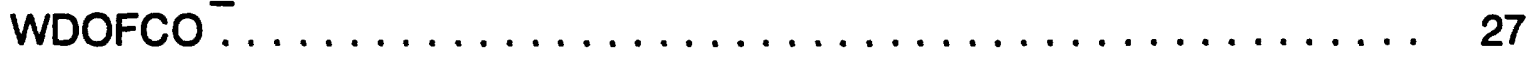

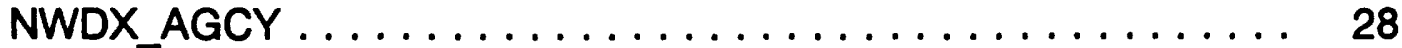

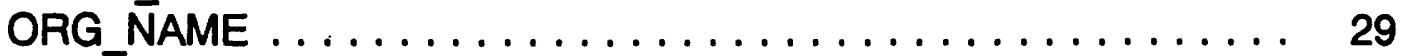

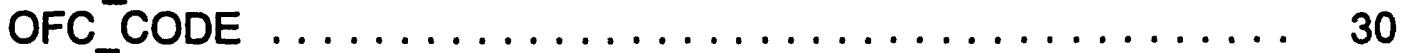

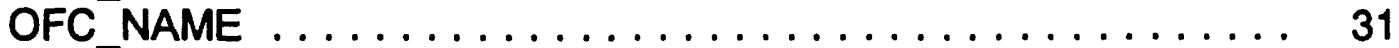

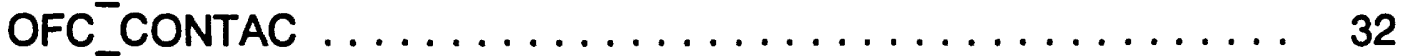

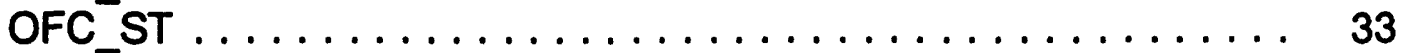

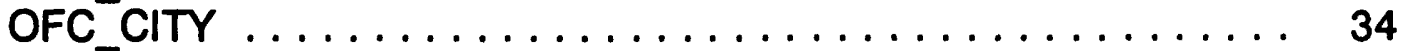

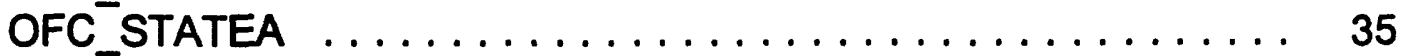

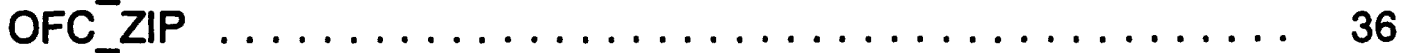

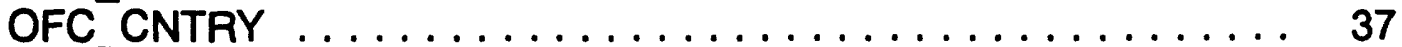

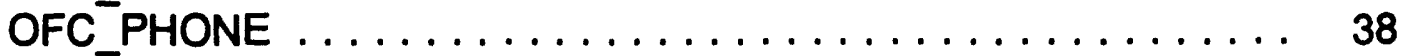

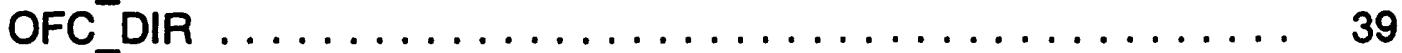

OFC_AREA $\ldots \ldots \ldots \ldots \ldots \ldots \ldots \ldots \ldots \ldots \ldots \ldots \ldots \ldots \ldots \ldots$

OFC_REQST $\ldots \ldots \ldots \ldots \ldots \ldots \ldots \ldots \ldots \ldots \ldots \ldots \ldots \ldots$

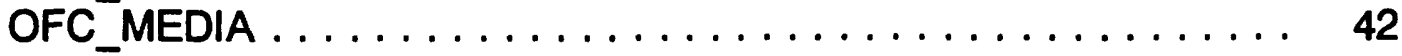

OFC_LFLAG $\ldots \ldots \ldots \ldots \ldots \ldots \ldots \ldots \ldots \ldots \ldots \ldots \ldots \ldots \ldots$

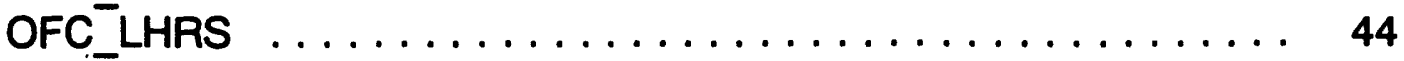




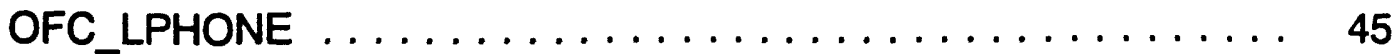

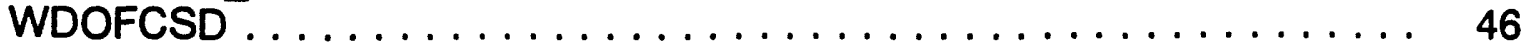

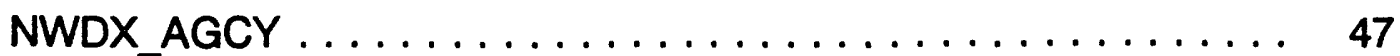

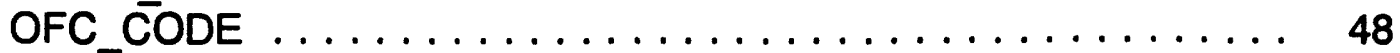

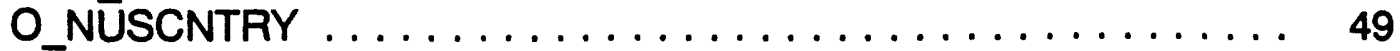

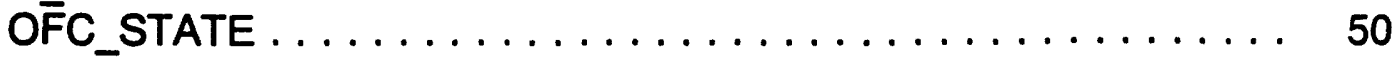

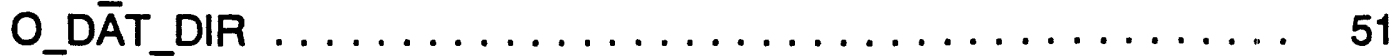

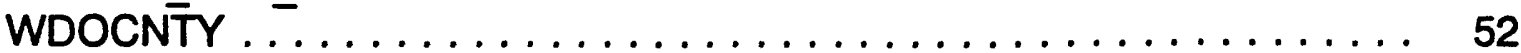

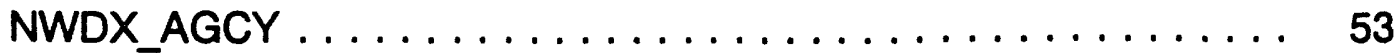

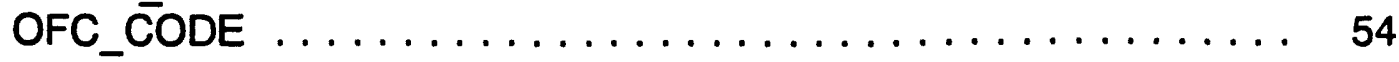

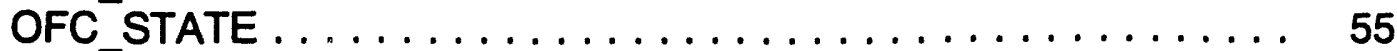

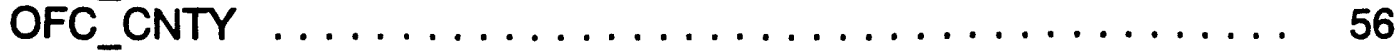

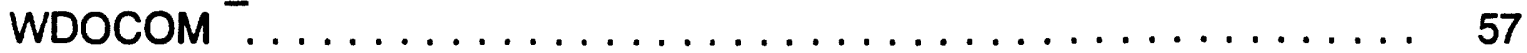

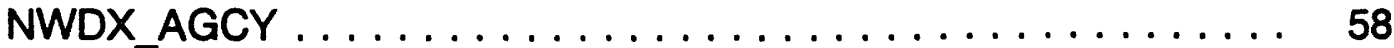

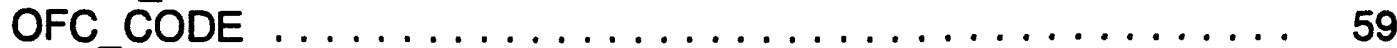

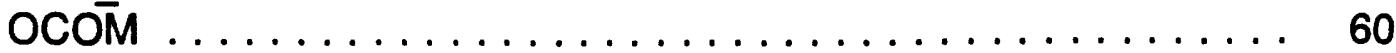

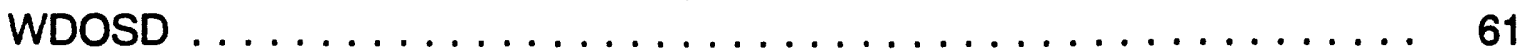

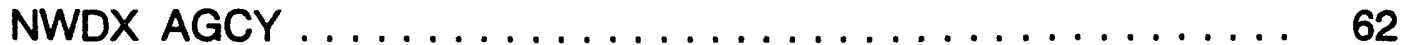

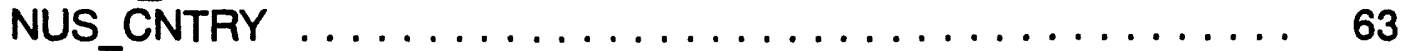

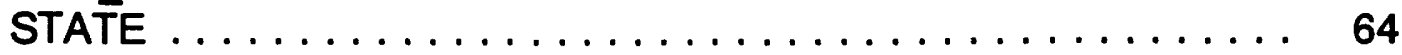

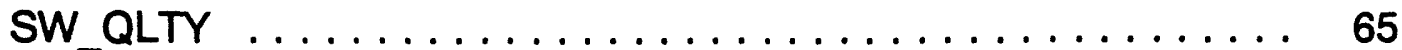

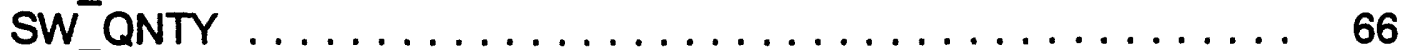

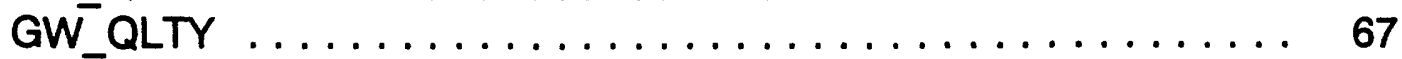

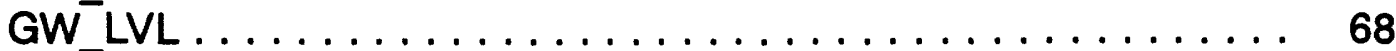

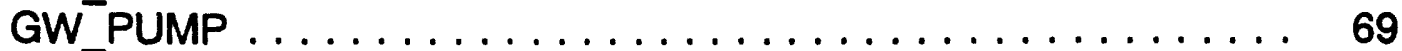

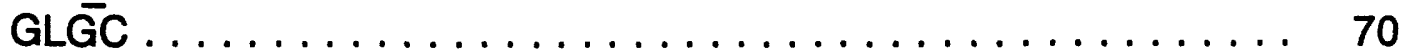

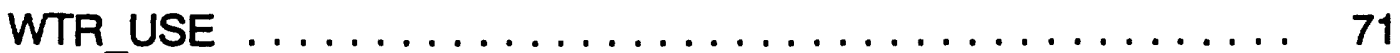

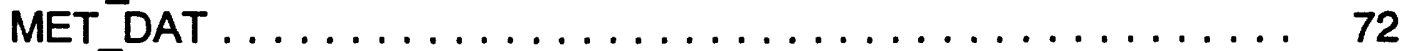

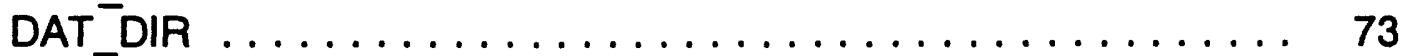

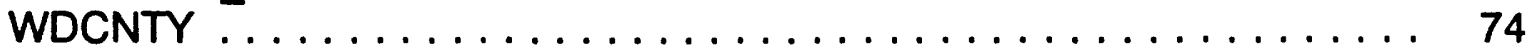

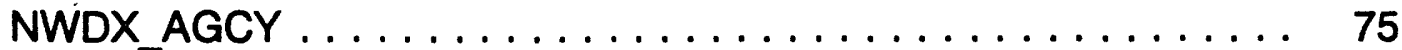

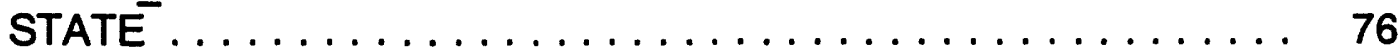

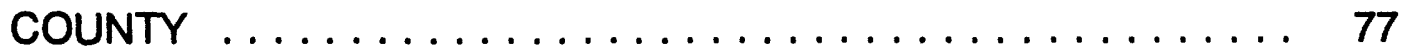

WDOS

(n) 78

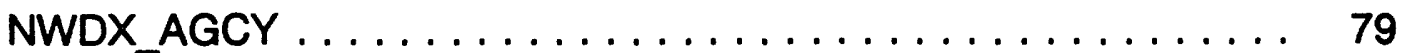

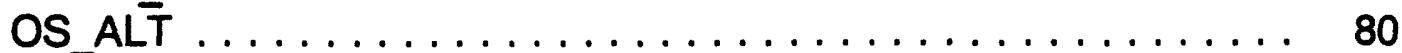

OS AGCY $\ldots \ldots \ldots \ldots \ldots \ldots \ldots \ldots \ldots \ldots \ldots \ldots \ldots \ldots \ldots$

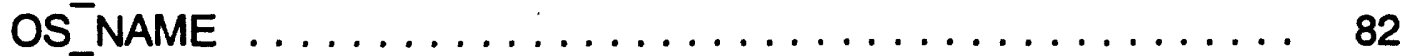

OS CONTAC ...................... 83

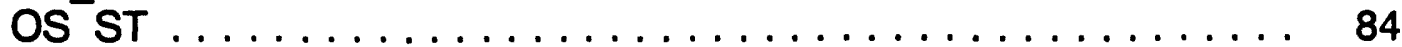

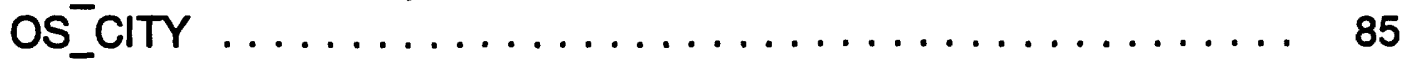

OS_STATE $\ldots \ldots \ldots \ldots \ldots \ldots \ldots \ldots \ldots \ldots \ldots \ldots$ 


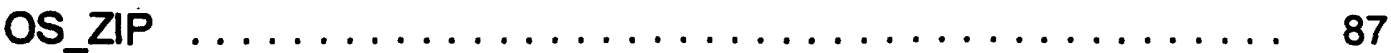

OS_CNTRY $\ldots \ldots \ldots \ldots \ldots \ldots \ldots \ldots \ldots \ldots \ldots \ldots \ldots$

OS_PHONE $\ldots \ldots \ldots \ldots \ldots \ldots \ldots \ldots \ldots \ldots \ldots \ldots \ldots$

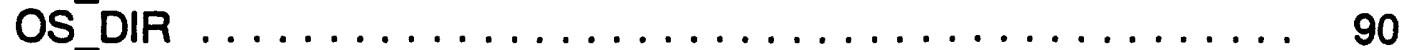

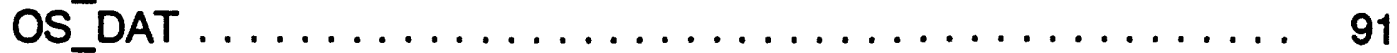

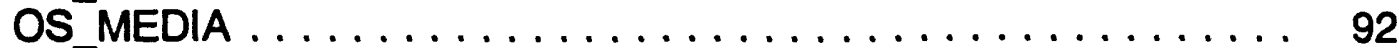

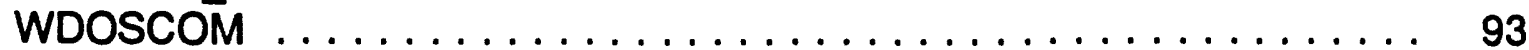

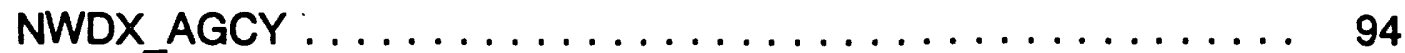

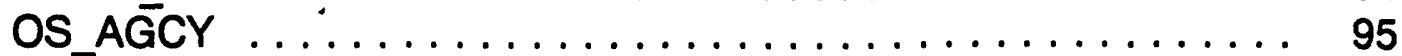

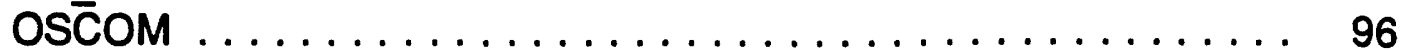

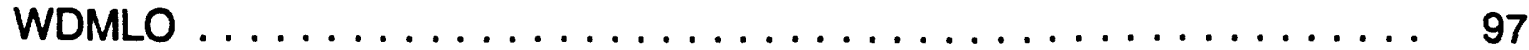

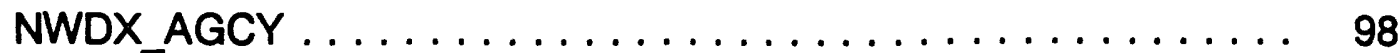

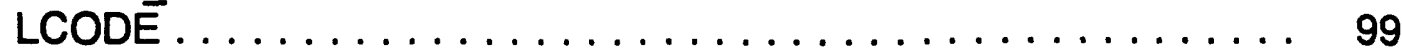

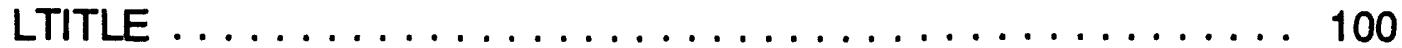

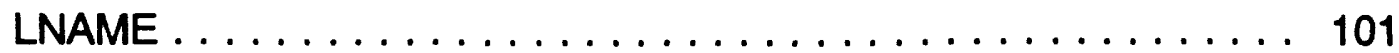

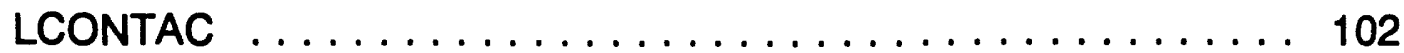

LSTREET $\ldots \ldots \ldots \ldots \ldots \ldots \ldots \ldots \ldots \ldots \ldots \ldots \ldots \ldots \ldots$

LCITY . . . . . . . . . . . . . . . . . . . . . . 104

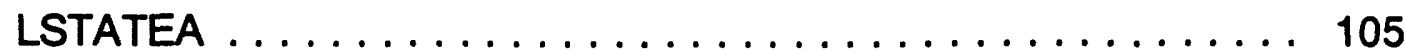

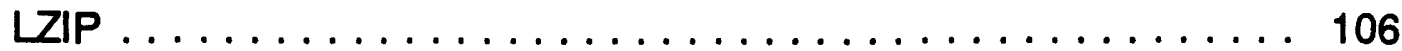

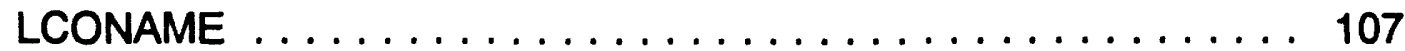

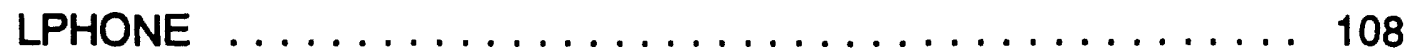

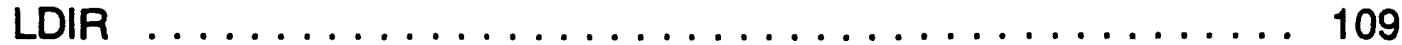

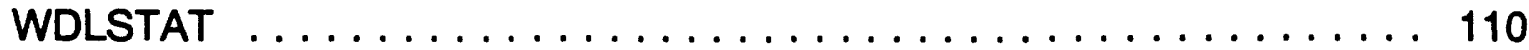

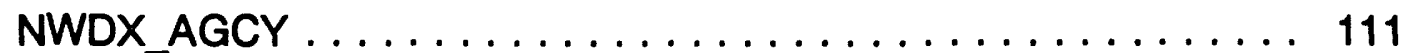

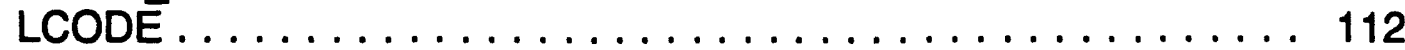

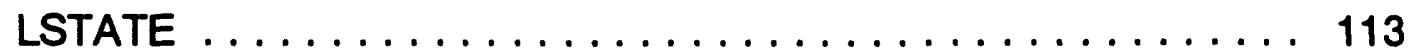

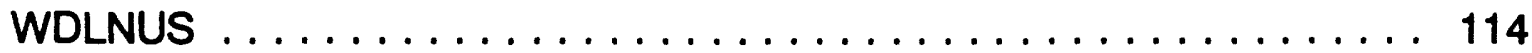

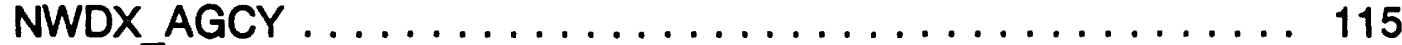

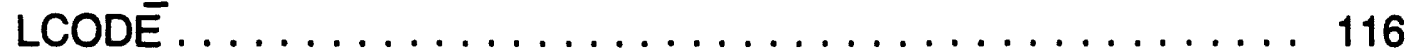

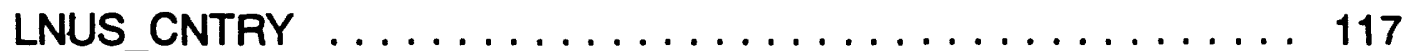

WDLCOM .............................. 118

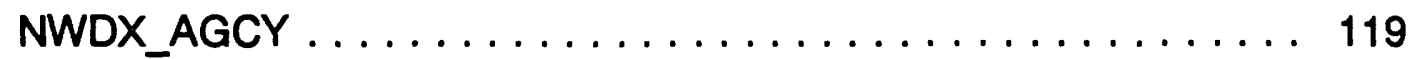

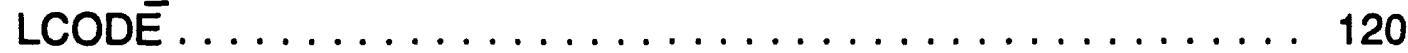

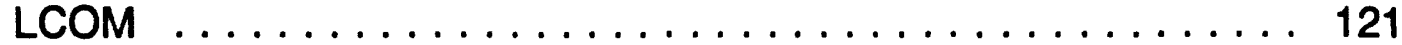

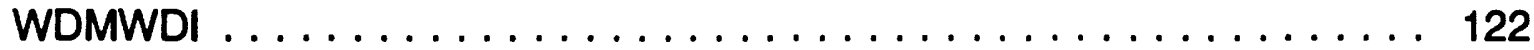

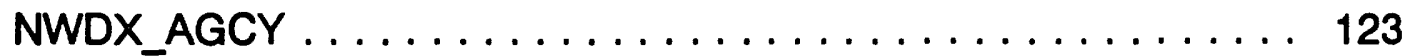

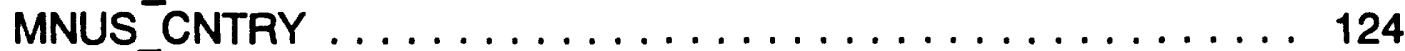

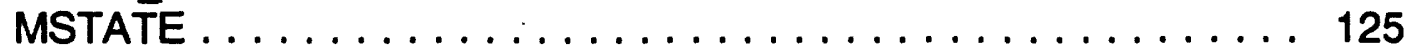

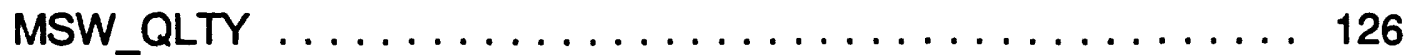

MSW_QNTY ......................... 127 
Page

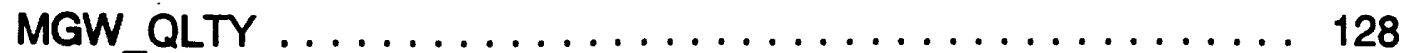

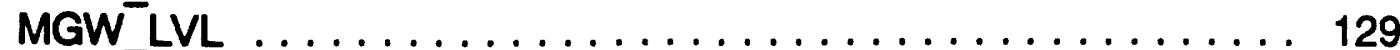

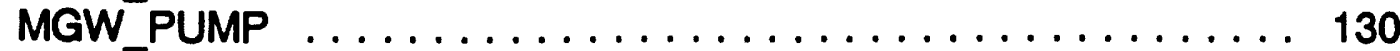

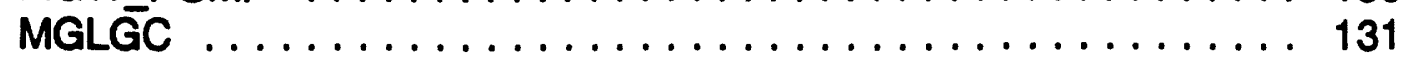

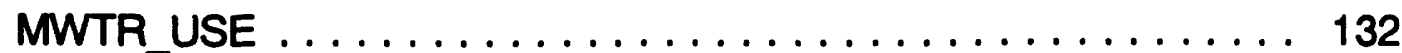

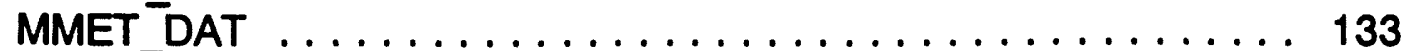

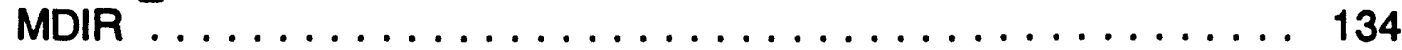

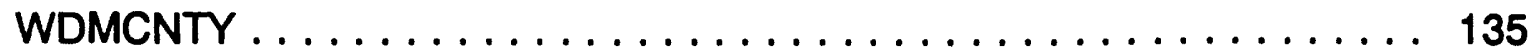

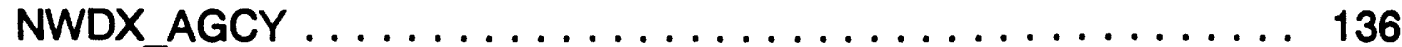

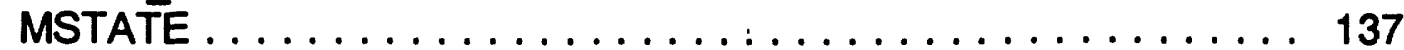

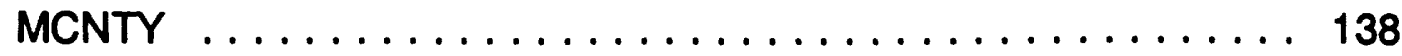

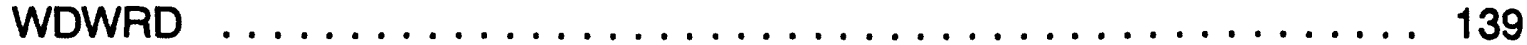

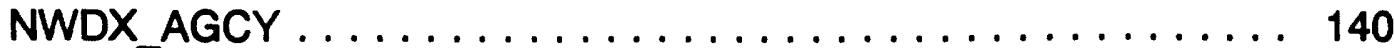

PARAM

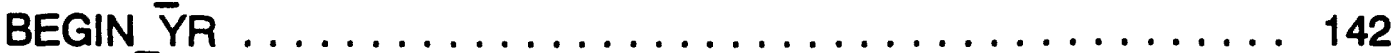

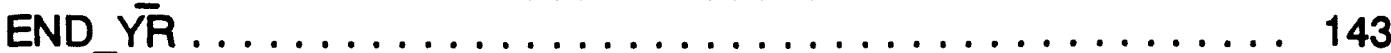

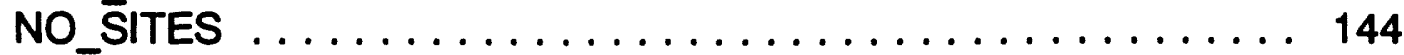

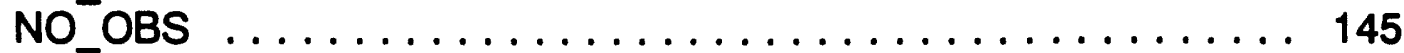

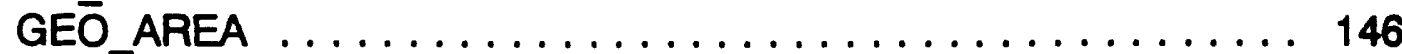

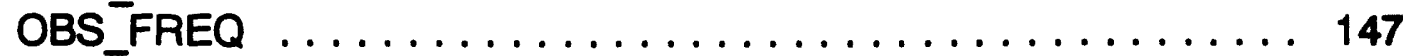

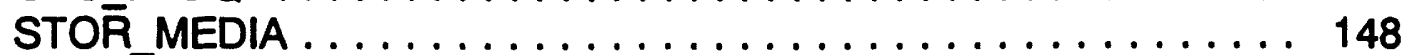

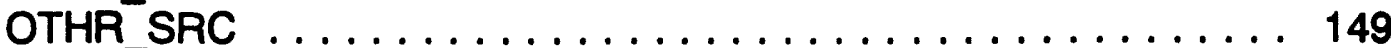

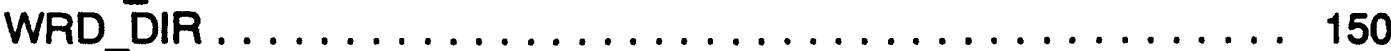

WDPARAM ............................ 151

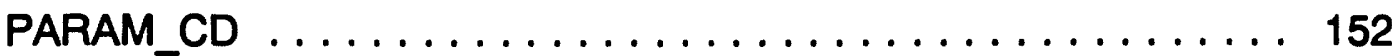

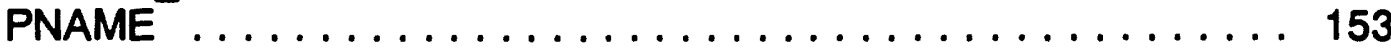

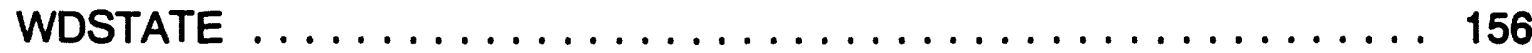

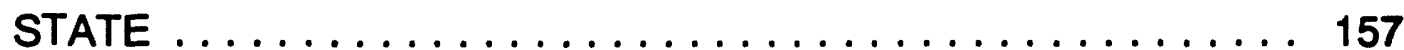

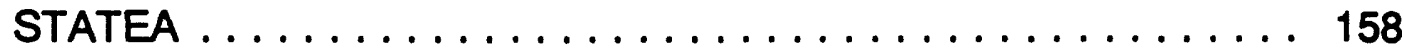

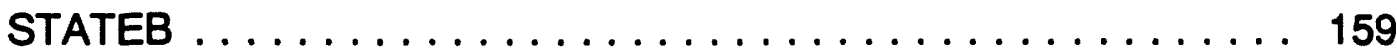

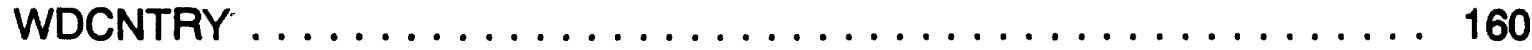

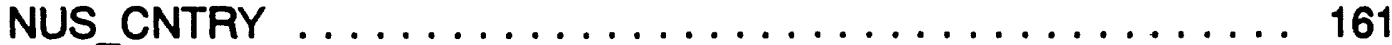

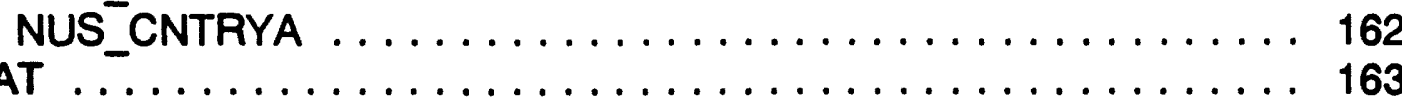

NWDX AGCY . . . . . . . . . . . . . . . . . . . . . 164

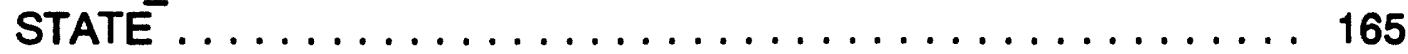

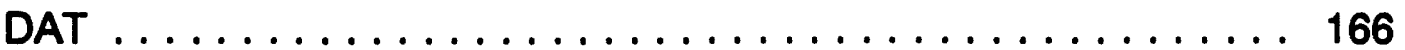

References

167 


\section{ILLUSTRATIONS}

Page

Figure 1. Hierarchical structure and contents of the Master Water Data Index . . . . . . . . . . . . . . . . 4

2. Relational database structure and contents of the Water

Data Sources Directory .................. 8

3. Format for a database file description $\ldots \ldots \ldots \ldots \ldots \ldots 11$

4. Format for a field description $\ldots \ldots \ldots \ldots \ldots \ldots \ldots \ldots$

\section{TABLES}

Table 1. Water Data Sources Directory Database File Descriptions .. 9

2. Water Data Sources Directory Support Database File Descriptions ........................... 10 


\section{PREFACE}

The National Water Data Exchange (NAWDEX) is an interagency program to facilitate the exchange of water data and promote the standardization of water-data-handling procedures. Participants in the NAWDEX program consist of federal, state, and local governmental organizations, and private organizations that collect and use water data.

NAWDEX maintains a Water Data Sources Directory (WDSD) which is a computerized index of water resources organizations. The original WDSD was a heirarchical database on the U.S. Geological Survey (USGS) mainframe computer. The WDSD was converted from a hierarchical design to a relational database design for the personal computer. The report describes the personal computer version. It describes the database files and fields of the new relational database design in dBASE IV for the personal computer.

This document is a revision of U.S Geological Survey Open File Report 82-923, "Definitions of the Components of the Water Data Sources Directory Maintained by the National Water Data Exchange," by Melvin D. Edwards. Open-File Report 82-923 describes the WDSD on the USGS mainframe computer.

The Directory provides answers to the following questions: What kinds of water data are available? Who has the data? Where can the data be obtained?

This document defines the database files and fields contained in the (WDSD); it is referred to as the "dictionary." Its purpose is to describe, in detail, the information in the WDSD.

Inquiries related to the dictionary may be directed to:

Chief

National Water Data Exchange

U.S. Geological Survey

421 National Center

Reston, Virginia 22092

Telephone: 703-648-5684

FTS 959-5684

${ }^{1}$ Use of brand names in this paper is for identification purposes only and does not constitute endorsement by the U.S. Geological Survey. 


\title{
DEFINITIONS OF DATABASE FILES AND FIELDS OF THE PERSONAL COMPUTER-BASED WATER DATA SOURCES DIRECTORY
}

\author{
By J. Wayne Green
}

\begin{abstract}
This report describes the database files and fields of the personal computer-based Water Data Sources Directory (WDSD). The personal computer-based WDSD was derived from the U.S. Geological Survery (USGS) mainframe computer version. The mainframe version of the WDSD is a hierarchical database design. The personal computer-based WDSD is a relational database design. This report describes the database files and fields of the relational database design in dBASE IV for the personal computer.
\end{abstract}

The WDSD contains information on (1) the type of organization, (2) the major orientation of water-data activities conducted by each organization, (3) the names, addresses, and telephone numbers of offices within each organization from which water data may be obtained, (4) the types of data held by each organization and the geographic locations within which these data have been collected, (5) alternative sources of an organization's data, (6) the designation of liaison personnel in matters related to water-data acquisition and indexing, (7) the volume of water data indexed for the organization, and (8) information about other types of data and services available from the organization that are pertinent to water-resource activities.

This document contains a definition and description of each database file and field of the WDSD database system. It will help users to update and retrieve data from the database. 


\section{INTRODUCTION}

\section{Background}

The personal computer-based Water Data Sources Directory (WDSD) is a relational database developed and maintained by the National Water Data Exchange (NAWDEX) Program Office. It contains information about organizations that collect, store, and disseminate water data and water-related data.

The personal computer-based WDSD was derived from the U.S. Geological Survery (USGS) mainframe computer version. The mainframe version of the WDSD is a heirarchical database design. The personal computer-based WDSD is relational database design. This report describes the database files and fields of the new relational database design in dBASE IV for the personal computer. Data from the mainframe computer were appended to dBASE IV for a personal computer.

The WDSD was redesigned to make the data more accessible to the user and to decrease the costs of using the mainframe computer.

The WDSD contains information on (1) the type of each organization, (2) the major orientation of water-data activities conducted by each organization, (3) the names, addresses, and telephone numbers of offices within each organization from which water data may be obtained, (4) the types of data held by each organization and the geographic locations within which these data have been collected, (5) alternative sources of an organization's data, (6) the designation of liaison personnel in matters related to waterdata acquisition and indexing, (7) the volume of water data indexed for the organization, and (8) information about other types of data and services available from the organization that are pertinent to water-resource activities.

The WDSD is designed to be used independently or in conjunction with the Master Water Data Index (MWDI). A few components in the MWDI are common to fields in the WDSD thereby cross-referencing retrieved information between the two databases. For example, a retrieval may be made from the MWDI to identify all sites within a geographic area of interest. A retrieval can then be made from the WDSD to determine the addresses from which data may be obtained from organizations operating the identified sites. The hierarchical structure and content of the MWDI appear in figure 1. 


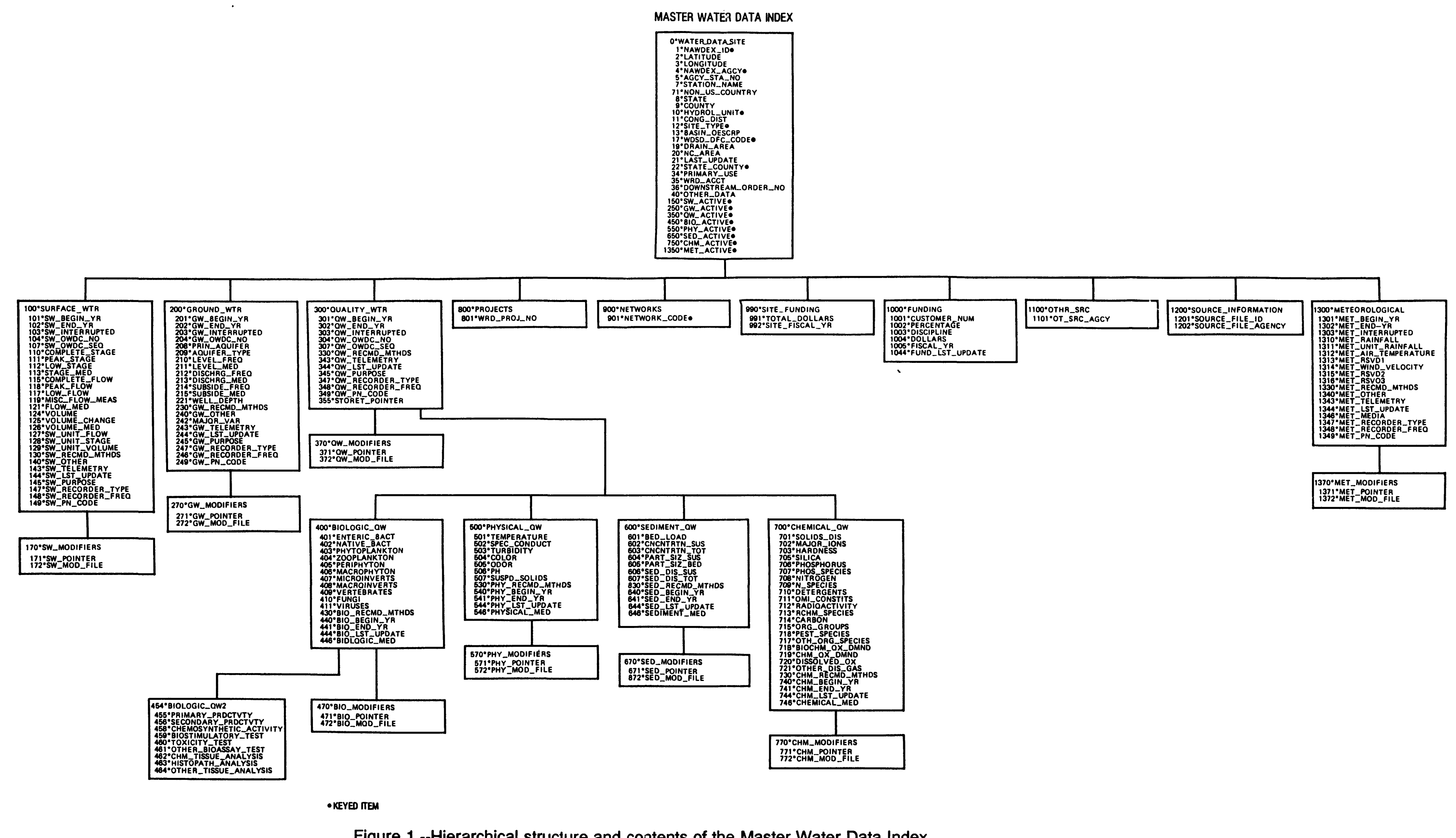

Figure 1.--Hierarchical structure and contents of the Master Water Data Index 



\section{Purpose and Scope}

This document defines the database files and fields of the personal computer-based Water Data Sources Directory (WDSD). The document presents: (1) the database structure, (2) the database file description, and (3) the database field description.

The report presents information to assist users in updating and retrieving data from the WDSD. 


\section{OVERVIEW OF THE WATER DATA SOURCES DIRECTORY}

\section{Data Base Description}

The Water Data Sources Directory (WDSD) contains the following general categories of information:

Organization Description

Unique identifier

Name of organization

NAWDEX membership

Type of organization

Orientation of the organization's activities

Office Description

Unique identifier

Name of office

Address

Telephone number

Areal coverage of data

Media used for data storage

State(s) and counties having data

General comments

Assistance Center information

Data Holdings of the Organization

Country, state, and counties for which data are available

Types of data available

Alternative Sources of the Organization's Data

Name of the alternative source

Address

Types of data available

Media used for data storage

General comments

Information about Liaison Officials for Water-Data Acquisition and Indexing Activities

Data Indexed in the MWDI

Water-Related Data Holdings of the Organization

Types of data available

Period of record 
Number of sites or observations

Geographic area covered

Frequency of measurement

Media used for data storage

Other organizations that are sources of the data

As the NAWDEX program progresses, additional groups of data, or additional data items, will be added to the WDSD. Future editions of this dictionary will reflect any additions or changes to the WDSD.

\section{Data Base Structure}

The WDSD relational database contains sixteen database files and four support database files as shown in figure 2. Each block in figure 2 represents a database file. The sixteen database files are described in table 1, and the four support database files are described in table 2.

Ashton-Tate's dBASE IV relational database management system manages and maintains the WDSD database. Fields are individual pieces of information, such as the name of an organization or the address of an office; database files contain logically related fields.

\section{HOW TO USE THIS DOCUMENT}

This document contains a detailed explanation of each database file and field of the WDSD. It is organized as is the WDSD database, with descriptions of fields belonging to the same database file located together. Each description of a database file or field in this document begins on a new page. The description of the fields associated with each database file follows the description of the database file. At the top of each page, certain attributes of the field defined are listed to provide information usually needed only by data processing personnel for software development. These attributes include IN DATABASE FILE, DATA TYPE, and LARGEST OR LONGEST VALUE. A full definition of each of these attributes is found below. For most users it will only be necessary to consider these attributes when producing a report or formulating a complex retrieval using dBASE IV. The attribute with which all users should be concerned is FIELD NAME. Figure 3 illustrates the format used to describe each database file. The following is an explanation of each attribute:

DATABASE FILE NAME - The name of the database file.

DATABASE FILE DEFINITION - A description of information available.

FIELDS - A list of fields included in the database file. 


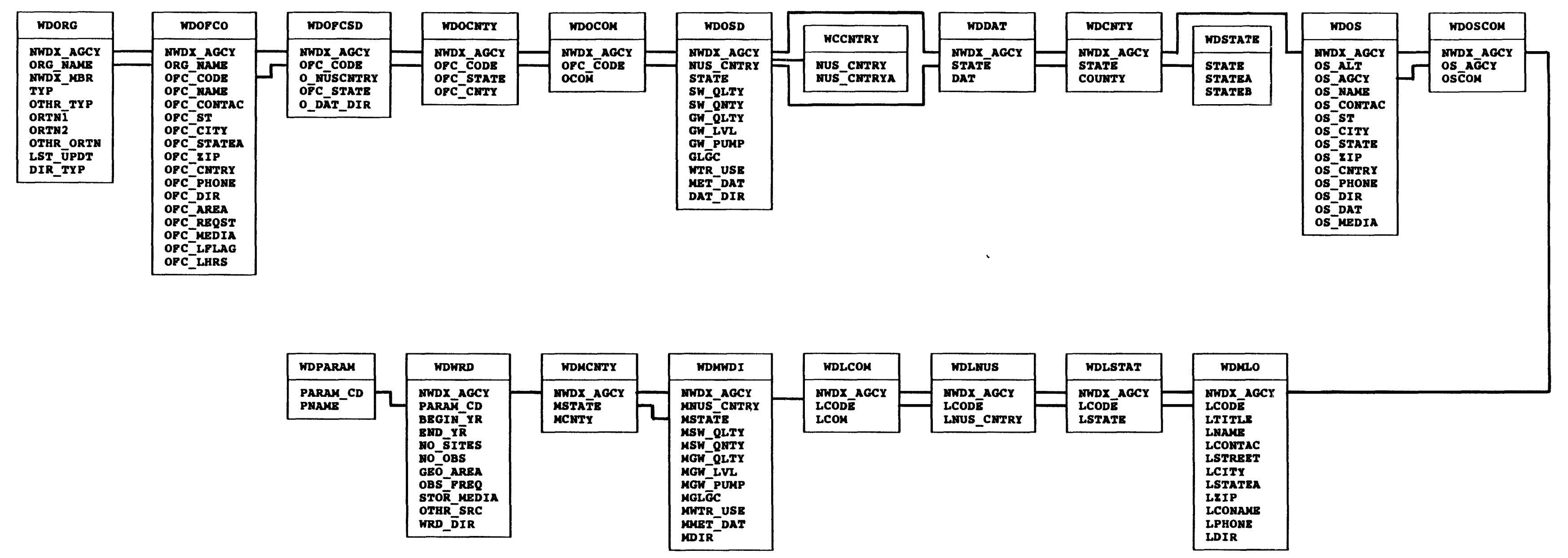

Figure 2.--Relational database structure and contents of the Water Data Sources Directory 

Table 1. -- Water Data Sources Directory Database File Descriptions

Database File

WDORG.dbf

WDOFCO.dbf

WDOFCSD.dbf

WDOCNTY.dbf

WDOCOM.dbf

WDOSD.dbf

WDCNTY.dbf

WDOS.dbf

WDOSCOM.dbf

WDMLO.dbf

WDLSTAT.dbf

WDLNUS.dbf

WDLCOM.dbf

WDMWDI.dbf

WDMCNTY.dbf

WDWRD.dbf

\section{Description}

Water-related activities of an organization

Office information about an organization

Geographic area covered by the data available from an office

Counties for which an office has data

General information about an office

Number and types of sites operated by an organization

Counties where the organization operates data collection sites

Other sources of an organization's data

General information about an other source organization

Persons to consult about water-data acquisition, coordination, and indexing activities

State location of the liaison contact

Country location of the liaison contact

General information about liaison activities

Number and type of sites indexed in the MWDI for an organization

Counties where the organization operates sites indexed in the MWDI

Water-related data that are collected and made available by an organization 
Table 2. -- Water Data Sources Directory Support Database File Descriptions

Database File

WDCNTRY.dbf

WDDAT.dbf

WDSTATE.dbf

WDPARAM.dbf

\section{Description}

Cross references a non-United States country code with its name

Cross references NAWDEX agency code, state numeric code, and type of site

Cross references a numeric state code with its name

Cross references a parameter code with its name 


\section{NAWDEX \\ WATER DATA SOURCES DIRECTORY \\ PERSONAL COMPUTER-BASED SYSTEM \\ DATA DICTIONARY}

DATABASE FILE NAME:

DATABASE FILE DEFINITION:

FIELDS:

Figure 3. Format for a database file description. 
Figure 4 illustrates the format for the field description. The following is an explanation of each attribute:

FIELD NAME - The unique name of the field as used in the database.

MANDATORY - Marked either Yes or No. If Yes, a value for the data field must be present in every occurrence in the database file. For example, the field NWDX_AGCY, is mandatory because it is the unique identification code of the organization and, therefore, must always be present. On the other hand, the field SW_QLTY, is not mandatory because not every organization operates surface water quality sites and, therefore, the data field may be non-valued.

DATA TYPE - Contains either CHARACTER, NUMERIC, or LOGICAL, depending on what type of data are stored for the field.

LARGEST OR LONGEST VALUE - This is the largest value that is allowed for the data field.

DATA VALUES - This is a narrative definition of the values that can be stored for a field.

GENERAL DESCRIPTION - This is a narrative description of the type of data stored for a field, its purpose, and the source or usefulness of the data. If a coding scheme is used, the meaning of each code is explained. 


\section{NAWDEX \\ WATER DATA SOURCES DIRECTORY \\ PERSONAL COMPUTER-BASED SYSTEM \\ DATA DICTIONARY}

FIELD NAME:

IN DATABASE FILE:

MANDATORY:

DATA TYPE:

LARGEST OR LONGEST VALUE:

DATA VALUES:

GENERAL DESCRIPTION:

Figure 4. Format for a field description. 
WATER DATA SOURCES DIRECTORY

(PERSONAL COMPUTER-BASED SYSTEM)

DATABASE FILE AND FIELD DEFINITIONS 
DATABASE FILE NAME:

DATABASE FILE DEFINITION:

FIELDS:
WDORG

Information that identifies and describes the water-related activities of the organization

NWDX AGCY

ORG NAME

NWDX_MBR

TYP

OTHR TYP

ORTN1

ORTN2

OTHR ORTN

LST UPDT

DIR_TYP 
FIELD NAME:

IN DATABASE FILE:

MANDATORY:

DATA TYPE:

LARGEST OR LONGEST VALUE: 5 characters
NWDX_AGCY

WDORG

Yes

Character

\section{DATA VALUES:}

The NAWDEX agency code varies in length from three to five characters. For federal organizations, it is US followed by a two-or three-character abbreviation of the organization's name. Values for non-federal organizations whose activities are within a given state boundary have a two-character state code followed by a NAWDEX-assigned sequence number. Values for non-federal organizations having activities at the multistate or national level have a three-to five-character abbreviation of the organization name (the characters US will not appear in the first two character positions). Alphabetic state codes are contained in the Federal Information Processing Standards (FIPS) Publication 5-1, dated June 15, 1970, "States and Outlying Areas of the United States." NAWDEX agency codes are presented in the publication, "Identification Codes for Organizations Listed in Computerized Data Systems of the U.S. Geological Survey" which may be obtained from the National Water Data Exchange, U.S. Geological Survey, 421 National Center, Reston, Virginia 22092. Telephone: (703) 648-6848; FTS 959-6848.

\section{GENERAL DESCRIPTION:}

The NAWDEX agency code is assigned by the NAWDEX Program Office and is the unique identifier for participating federal and non-federal organizations that actively collect and store water data. Non-federal organizations include state, county, and municipal agencies, as well as intergovernmental compacts, private organizations, universities, and any local organizations at other than county or municipal level. 
FIELD NAME:

IN DATABASE FILE:

MANDATORY:

DATA TYPE:

LARGEST OR LONGEST VALUE:
ORG_NAME

WDORG

Yes

Character

40 characters

\section{DATA VALUES:}

The name of the organization contains up to $\mathbf{4 0}$ characters.

\section{GENERAL DESCRIPTION:}

The name is the official name of the organization as it should appear on correspondence addressed to the organization. 
FIELD NAME:

IN DATABASE FILE:

MANDATORY:

DATA TYPE:

LARGEST OR LONGEST VALUE: $\quad \mathrm{Y}$ or $\mathrm{N}$
NWDX_MBR

WDORG

Yes

Logical

\section{DATA VALUES:}

This field contains " $N$ " if the organization is not a member of NAWDEX or " $\mathrm{"} \mathrm{if} \mathrm{it} \mathrm{is} \mathrm{a}$ member.

\section{GENERAL DESCRIPTION:}

Membership in NAWDEX is voluntary and open to any water-oriented organization that wishes to take an active role in its activities. To be a member, one must sign Memorandum of Understanding between the NAWDEX Program Office and the member organization. 
FIELD NAME:

IN DATABASE FILE:

MANDATORY:

DATA TYPE:

LARGEST OR LONGEST VALUE:
TYP

WDORG

Yes

Character

One-letter NAWDEX TYP code

\section{DATA VALUES:}

The TYP field contains a code used to classify an organization into one of the groups explained below.

\section{GENERAL DESCRIPTION:}

Code Meaning

C County - A single organization, typically governmental, whose scope of activity is encompassed by the boundaries of one or more counties but does not cover an entire state.

$\mathbf{F}$

Federal - An agency or agencies of the federal government or a multicountry organization operating at the federal level.

G

Intergovernmental - An organization made up of different government agencies, such as federal-state compacts, state-state compacts, multicounty compacts, and river basin commissions. The scope of all the agencies involved is only within the United States.

International - An organization made up of representatives from different countries, such as UNESCO and WHO.

L Local - A local governmental organization other than county or municipal.

M Municipal - A single municipal governmental organization.

P Private - An organization that cannot be classified as a governmental organization.

S State - A single governmental organization whose scope of activity is encompassed by the boundaries of a single state. 
Code

U

0
Meaning

University or Research Institute - An educational institution (public or private) at the university or college level, or a non-profit organization engaged in research.

Other - An organization that cannot be classified into one of the other groups. If this field is valued as "O" then field OTHR_TYP contains a description of the type of organization. 
FIELD NAME:

IN DATABASE FILE:

MANDATORY:

DATA TYPE:

LARGEST OR LONGEST VALUE:
OTHR_TYP

WDORG

No

Character

12 characters

\section{DATA VALUES:}

If the organization is a type that cannot be classified into one of the groups in field TYP, then this field contains a description of the type of organization up to 12 characters in length. It is valued only if the TYP field is valued as " $O$ " (Other).

\section{GENERAL DESCRIPTION:}

The NAWDEX Program Office enters the descriptions of other types of organizations based on information supplied by the organizations. 
FIELD NAME:

ORTN1

IN DATABASE FILE:

WDORG

MANDATORY:

Yes

DATA TYPE:

Character

LARGEST OR LONGEST VALUE: One-character NAWDEX orientation code DATA VALUES:

This field contains a code that describes the primary orientation of the organization's water-related activities.

GENERAL DESCRIPTION:

Code Meaning
A Agriculture and Irrigation
B Basic Hydrologic Research
D Domestic, Rural
E Evaluation of Resources
F Flood Control
H Hydroelectric
I Industry
M Multiple Source Public Supply
$N \quad$ Navigation
P Pollution Studies
R Recreation
S Single Source Public Supply
$T \quad$ Thermoelectric
W Fish and Wildlife
O Other

If this field is valued as "O" then field OTHR_ORTN (other types of orientation described on page 24) contains a description of the orientation of the organization's water-related activities. 
FIELD NAME:

ORTN2

IN DATABASE FILE:

WDORG

MANDATORY:

No

LARGEST OR LONGEST VALUE: One-character NAWDEX orientation code

DATA VALUES:

This field contains a code that describes the secondary orientation of the organization's water-related activities if a single designation in field ORTN1 is inadequate to describe those activities.

\section{GENERAL DESCRIPTION:}

The fields ORTN1 and ORTN2 use the same codes. 
FIELD NAME:

IN DATABASE FILE:

MANDATORY:

DATA TYPE:

LARGEST OR LONGEST VALUE:
OTHR_ORTN

WDORG

No

Character

12 characters

\section{DATA VALUES:}

This field contains up to a 12-character description of the orientation of the organization's water-related activities. It is valued only if ORTN1 is valued as "O" (Other).

\section{GENERAL DESCRIPTION:}

The NAWDEX Program Office enters descriptions of other types of orientations based on information supplied by the reporting organization. 
FIELD NAME:

IN DATABASE FILE:

MANDATORY:

DATA TYPE:

LARGEST OR LONGEST VALUE:
LST_UPDT

WDORG

Yes

Character

10 characters

\section{DATA VALUES:}

This field contains the month, day, and year of the last date (MM/DD/YYYY) that an update of any type was processed against the organization's entry in the database.

\section{GENERAL DESCRIPTION:}

An update is any transaction that adds, deletes, or changes data values in the WDSD database. If no updates have been made to the data about an organization, the LST_UPDT is the date on which the data was first inserted into the database. 
FIELD NAME:

IN DATABASE FILE:

MANDATORY:

DATA TYPE:

LARGEST OR LONGEST VALUE: 10 characters
DIR_TYP

WDORG

Yes

Character

DATA VALUES:

Code Meaning
W Water Data Sources Directory
R Water-Related Data Sources Directory
O Directory of Water Resources Organizations
$L \quad$ Directory of Liaison Officials
I Directory of Indexing Officials
$\mathrm{N} \quad$ Directory of Water-Use Liaison Officials

\section{GENERAL DESCRIPTION:}

The DIR_TYP field contains a combination of 1 to 10 codes, left-justified. This field is used in retrieving specified types of directories. Each code may occur only once in this field. The NAWDEX Program Office will add codes, as the need arises, to meet future directory needs. 
DATABASE FILE NAME:

DATABASE FILE DEFINITION:

FIELDS:
WDOFCO

Information about one or more offices of the organization, including the office's address and telephone number, and the areal coverage of the data owned by the office. Contains the telephone number and operating hours of assistance centers.

The primary purpose of this database file is to provide information to NAWDEX users about offices that can and will supply their data upon request.

NWDX_AGCY
ORG_NAME
OFC_CODE
OFC_NAME
OFC_CONTAC
OFC_ST
OFC_CITY
OFC_STATEA
OFC_ZIP
OFC_CNTRY
OFC_PHONE
OFC_DIR
OFC_AREA
OFC_REQST
OFC_MEDIA
OFC_LFLAG
OFC_LHRS
OFC_LPHONE


FIELD NAME:

IN DATABASE FILE:

MANDATORY:

DATA TYPE:

LARGEST OR LONGEST VALUE: 5 characters
NWDX_AGCY

WDOFCO (Also in WDORG)

Yes

Character

\section{DATA VALUES:}

The NAWDEX agency code varies in length from three to five characters. For federal organizations, it is US followed by a two- or three-character abbreviation of the organization's name. Values for non-federal organizations whose activities are within a given state boundary have a two-character state code followed by a NAWDEX-assigned sequence number. Values for non-federal organizations having activities at the multistate or national level have a three-to five-character abbreviation of the organization name (the characters US will not appear in the first two character positions). Alphabetic state codes are contained in the Federal Information Processing Standards (FIPS) Publication 5-1, dated June 15, 1970, "States and Outlying Areas of the United States." NAWDEX agency codes are presented in the publication, "Identification Codes for Organizations Listed in Computerized Data Systems of the U.S. Geological Survey" which may be obtained from the National Water Data Exchange, U.S. Geological Survey, 421 National Center, Reston, Virginia 22092. Telephone: (703) 648-6848; FTS 959-6848.

\section{GENERAL DESCRIPTION:}

The NAWDEX agency code is assigned by the NAWDEX Program Office and is the unique identifier for participating federal and non-federal organizations that actively collect and store water data. Non-federal organizations include state, county, and municipal agencies, as well as intergovernmental compacts, private organizations, universities, and any local organizations at other than county or municipal level. 
FIELD NAME:

IN DATABASE FILE:

MANDATORY:

DATA TYPE:

LARGEST OR LONGEST VALUE: $\quad 40$ characters

DATA VALUES:

The name of the organization contains up to $\mathbf{4 0}$ characters.

GENERAL DESCRIPTION:

The name is the official name of the organization as it should appear on correspondence addressed to the organization.
ORG_NAME

WDOFCO (Also in WDORG)

Yes

Character 
FIELD NAME:

IN DATABASE FILE:

MANDATORY:

DATA TYPE:

LARGEST OR LONGEST VALUE:
OFC_CODE

WDOFCO

Yes

Character

9 characters

\section{DATA VALUES:}

The NAWDEX Program Office assigns the OFC_CODE field. The first two characters of the code consists of two digits representing the state or two letters representing the country in which the office is located; the next five characters consist of five digits representing the city or place in which the office is located; and the last two characters consist of an arbitrary two-digit sequence number to uniquely identify multiple offices within the same city or place. A complete list of country codes is contained in the Federal Information Processing Standards (FIPS) Publication 10-2, "Countries, Dependencies, and Areas of Special Sovereignty," dated 1976; a complete list of state codes is contained in the Federal Information Processing Standards (FIPS) Publication 5-1, "States and Outlying Areas of the United States," dated 1970; and a complete list of city and place codes is contained in the Federal Information Processing Standards (FIPS) Publication 55, "Codes for Named Populated Places and Related Entities of the State of the United States," dated 1978.

\section{GENERAL DESCRIPTION:}

This field is used to retrieve addresses of operating offices from the WDSD database. The code for an office is unique within an organization but is not necessarily unique across the database. Its counterpart in the MWDI database is component number 17 , WDSD_OFC_CODE. 
FIELD NAME:

OFC_NAME

IN DATABASE FILE:

WDOFCO

MANDATORY:

No

DATA TYPE:

Character

LARGEST OR LONGEST VALUE: $\quad 40$ characters

DATA VALUES:

This field contains the name of the office.

GENERAL DESCRIPTION:

This field contains the official name of the office. If the organization has only a single office, this field may be the same as the ORG_NAME field. 
FIELD NAME:

IN DATABASE FILE:

MANDATORY:

DATA TYPE:

LARGEST OR LONGEST VALUE:

DATA VALUES:

This field contains the name of the contact person.

GENERAL DESCRIPTION:

The office contact is the name or title of the person or office a requester contacts for obtaining the office's data that are indexed in NAWDEX.

32 
FIELD NAME:

IN DATABASE FILE:

MANDATORY:

DATA TYPE:

LARGEST OR LONGEST VALUE: $\quad \mathbf{4 0}$ characters

DATA VALUES:

This field contains up to $\mathbf{4 0}$ characters.

\section{GENERAL DESCRIPTION:}

This field contains the street address or post office box number of the office contact named in the field, OFC_CONTAC. A requester should send a letter to this address requesting the office's data indexed in NAWDEX. 
FIELD NAME:

IN DATABASE FILE:

MANDATORY:

DATA TYPE:

LARGEST OR LONGEST VALUE: 30 characters

DATA VALUES:

This field contains the name of the city up to 30 characters.

GENERAL DESCRIPTION:

The office is located in this city. The city name accompanies the address and, therefore, should be the name of the city used for mailing.

34 
FIELD NAME:

IN DATABASE FILE:

MANDATORY:

DATA TYPE:

LARGEST OR LONGEST VALUE: WY
OFC_STATEA

WDOFCO

No

Character

\section{DATA VALUES:}

This field contains a two-character postal code identifying the state in which the office is located.

\section{GENERAL DESCRIPTION:}

Postal codes are alphabetic state abbreviations recognized by the U.S. Postal Service as part of a mailing address. The OFC_STATEA field should be valued only if the office is located within the United States or one of its territories. If the office is outside the United States, this field is not valued. 
FIELD NAME:

IN DATABASE FILE:

MANDATORY:

DATA TYPE:

LARGEST OR LONGEST VALUE:
OFC_ZIP

WDOFCO

No

Character

\section{DATA VALUES:}

This field contains up to ten digits and/or characters which is the U.S. Postal ZIP code or foreign postal code of the organization.

\section{GENERAL DESCRIPTION:}

The ZIP code is a geographic code that identifies areas within the United States and its possessions for simplifying the distribution of mail by the U.S. Postal Service. The ZIP code alinements do not adhere to boundaries of cities, counties, states, or other jurisdictions. For organizations outside the United States and its territories, the foreign postal code, if applicable, will be defined in the format of its local usage. 
FIELD NAME:

IN DATABASE FILE:

MANDATORY:

DATA TYPE:

LARGEST OR LONGEST VALUE: 30 Characters
OFC_CNTRY

WDOFCO

No

Character

DATA VALUES:

This field contains the name of the country in which the office is located. If the office is in the United States, the abbreviation "USA" is used. For countries other than the United States, the full name of the country is stored.

\section{GENERAL DESCRIPTION:}

The name of the country applies to the country in which the office is physically located. It is the name that is part of the mailing address on correspondence addressed to the office. It bears no relationship to the data holdings of the office. 
FIELD NAME:

IN DATABASE FILE:

MANDATORY:

DATA TYPE:

LARGEST OR LONGEST VALUE:

\section{OFC_PHONE}

WDOFCO

No

Character

999-999-9999

\section{DATA VALUES:}

This is the telephone number of the office. If the office is within the United States or one of its territories, the number consists of a three-digit area code, followed by a dash, and followed by the seven digits of the local telephone number. A dash appears between the third and fourth digits of the local number. If the office is outside the United States, whatever format is required is the one used to store the correct telephone number.

\section{GENERAL DESCRIPTION:}

This is the telephone number at which the office and its contact can be reached. 
FIELD NAME:

IN DATABASE FILE:

MANDATORY:

DATA TYPE:

LARGEST OR LONGEST VALUE:
OFC_DIR

WDOFCO

Yes

Character

10 characters

\section{DATA VALUES:}

Code Meaning
W
Water Data Sources Directory
R
Water-related Data Sources Directory
O Directory of Water Resources Organizations

\section{GENERAL DESCRIPTION:}

The OFC_DIR field contains a combination of 1 to 10 codes, left-justified, used in retrieving specified types of directories. Each code may occur only once in this field. The NAWDEX Program Office will add codes, as the need arises, to meet future directory needs. 
FIELD NAME:

OFC_AREA

IN DATABASE FILE:

WDOFCO

MANDATORY:

No

DATA TYPE:

Character

LARGEST OR LONGEST VALUE: S

DATA VALUES:

This field contains a code that describes the geographic area encompassed by the data available from the office.

\section{GENERAL DESCRIPTION:}

Code $\quad$ Meaning

A Multicounty - Two or more counties, all in the same state, but not encompassing the entire state.

C One County - All the available data are for a single county.

Multicountry, International - Data from more than one country are available.

M Multistate (Province) - Data from more than one state or province are available, and all data are for a single country.

N Nationwide - The available data span an entire country and are limited to that single country.

S Statewide - The available data span an entire state and are limited to that single state (or province). 
FIELD NAME:

IN DATABASE FILE:

MANDATORY:

DATA TYPE:

LARGEST OR LONGEST VALUE: $\mathrm{Y}$ or $\mathrm{N}$
OFC_REQST

WDOFCO

Yes

Character

\section{DATA VALUES:}

This field contains " $Y$ " if the office responds to requests for data and " $\mathrm{N}$ " if it does not.

\section{GENERAL DESCRIPTION:}

Offices that collect and/or store water data may or may not choose to furnish that data to those who request it. If the office does respond to requests for its data, then this field contains " $Y$ ". This information is furnished to users of NAWDEX so that they can ascertain if the office can be contacted to obtain data.

If the office does not respond to requests for its data, it is still included in the WDSD for administrative purposes, and this field contains "N". Frequently offices that do not respond to requests for data furnish their data to one or more organizations that do respond to requests. When this is the case, information about the alternative source of data is contained in WDOS. 
FIELD NAME:

IN DATABASE FILE:

MANDATORY:

DATA TYPE:

LARGEST OR LONGEST VALUE:

DATA VALUES:

This field contains a code that describes the type(s) of media used to store the office's hydrologic data.

\section{GENERAL DESCRIPTION:}

Code Meaning

C Computer recognizable - The data are stored on media that can be read by a computer. This might be punched cards, paper tape, magnetic disk, drum, or some similar device.

D Computer and published - Data are stored in both computer recognizable and published form.

E Computer and microform - Data are stored in both computer recognizable and microform formats.

$\mathbf{F}$

Computer, published, and microform -Data are stored in computer recognizable, published, and microform formats.

G

M

$\mathbf{P}$
OFC_MEDIA

WDOFCO

No

Character 
FIELD NAME:

IN DATABASE FILE:

MANDATORY:

DATA TYPE:
OFC_LFLAG

WDOFCO

No

Character

\section{LARGEST OR LONGEST VALUE: 1}

\section{DATA VALUES:}

This field contains " 1 " if the office is a NAWDEX Assistance Center. Otherwise, it has no value.

\section{GENERAL DESCRIPTION:}

The purpose of this field is to identify offices that are assistance centers for the NAWDEX program. A nationwide network of assistance centers support the service capabilities of NAWDEX. These centers were set up in offices of NAWDEX members to provide local and convenient access to NAWDEX and its services. Most are equipped with computer terminals, thereby providing an extensive telecommunications network for access to the computerized directory and indexes being developed for the NAWDEX program. As the NAWDEX membership increases, additional centers will be added in large population areas and areas of high user interest to provide more optimal access to NAWDEX and its services. A complete directory of assistance centers may be obtained from the National Water Data Exchange, U.S. Geological Survey, 421 National Center, Reston, Virginia 22092. 
FIELD NAME:

IN DATABASE FILE:

MANDATORY:

DATA TYPE:

LARGEST OR LONGEST VALUE: 20 characters
OFC_LHRS

WDOFCO

Yes

Character

\section{DATA VALUES:}

The hours of operation of an Assistance Center are given in this way:

As shown in the following, the first three characters show the time zone, standardized to Greenwich Mean Time; the fourth character is a blank.

\begin{tabular}{|c|c|}
\hline United States Time Zone & $\begin{array}{l}\text { Greenwich } \\
\text { (First Three }\end{array}$ \\
\hline $\begin{array}{l}\text { Atlantic } \\
\text { Eastern } \\
\text { Central } \\
\text { Mountain } \\
\text { Pacific } \\
\text { Yukon } \\
\text { Alaska-Hawaii } \\
\text { Bering }\end{array}$ & $\begin{array}{l}+04 \\
+05 \\
+06 \\
+07 \\
+08 \\
+09 \\
+10 \\
+11\end{array}$ \\
\hline
\end{tabular}

The following abbreviations are also incorporated: SU for Sunday; $M$ for Monday; $T$ for Tuesday; $W$ for Wednesday; TH for Thursday; $F$ for Friday; $S$ for Saturday. Thus, the following would be for an office in the Central Time Zone in the U.S.A. which is open from 9 a.m. to 3 p.m. on Monday through Thursday, and 9 a.m. to 2 p.m. on Friday:

$$
+06 \mathrm{M}-\mathrm{TH} 9-3 \mathrm{~F} 9-2
$$

\section{GENERAL DESCRIPTION:}

This field contains information about the hours during which someone is available at an Assistance Center to respond to requests for data. 
FIELD NAME:

IN DATABASE FILE:

MANDATORY:

DATA TYPE:

LARGEST OR LONGEST VALUE:
OFC_LPHONE

WDOFCO

Yes

Character

999-999-9999

\section{DATA VALUE:}

This field contains the telephone number of the Assistance Center. If the office is within the United States or one of its territories, the number consists of a three-digit area code, followed by a dash, followed by seven digits of the local telephone number. A dash appears between the third and fourth digits of the local number. If the office is outside the United States, whatever format is required is the one used.

\section{GENERAL DESCRIPTION:}

This field contains the telephone number at which the Assistance Center can be reached for requesting information from NAWDEX. It may differ from the telephone number in the OFC_PHONE field because OFC_PHONE is the number to call to request data and index information from NAWDEX. 
DATABASE FILE NAME:

DATABASE FILE DEFINITION:

FIELDS:
WDOFCSD

Information about the geographic area covered by the data available from the office

NWDX AGCY

OFC CODE

O NÜSCNTRY

OFFC STATE

O_DĀT_DIR 
FIELD NAME:

IN DATABASE FILE:

MANDATORY:

DATA TYPE:

\section{LARGEST OR LONGEST VALUE:}

NWDX_AGCY

WDOFCSD

Yes

Character

5 characters

\section{DATA VALUES:}

The NAWDEX agency code varies in length from three to five characters. For federal organizations, it is US followed by a two- or three-character abbreviation of the organization's name. Values for non-federal organizations whose activities are within a given state boundary have a two-character state code followed by a NAWDEX-assigned sequence number. Values for non-federal organizations having activities at the multistate or national level have a three-to five-character abbreviation of the organization name (the characters US will not appear in the first two character positions). Alphabetic state codes are contained in the Federal Information Processing Standards (FIPS) Publication 5-1, dated June 15, 1970, "States and Outlying Areas of the United States." NAWDEX agency codes are presented in the publication, "Identification Codes for Organizations Listed in Computerized Data Systems of the U.S. Geological Survey" which may be obtained from the National Water Data Exchange, U.S. Geological Survey, 421 National Center, Reston, Virginia 22092. Telephone: (703) 648-6848; FTS 959-6848.

\section{GENERAL DESCRIPTION:}

The NAWDEX agency code is assigned by the NAWDEX Program Office and is the unique identifier for participating federal and non-federal organizations that actively collect and store water data. Non-federal organizations include state, county, and municipal agencies, as well as intergovernmental compacts, private organizations, universities, and any local organizations at other than county or municipal level. 
FIELD NAME:

IN DATABASE FILE:

MANDATORY:

DATA TYPE:

\section{LARGEST OR LONGEST VALUE: 9 characters}

OFC_CODE

WDOFCSD

Yes

Character

\section{DATA VALUES:}

The NAWDEX Program Office assigns the OFC_CODE field. The first two characters of the code consists of two digits representing the state or two letters representing the country in which the office is located; the next five characters consist of five digits representing the city or place in which the office is located; and the last two characters consist of an arbitrary two-digit sequence number to uniquely identify multiple offices within the same city or place. A complete list of country codes is contained in the Federal Information Processing Standards (FIPS) Publication 10-2, "Countries, Dependencies, and Areas of Special Sovereignty," dated 1976; a complete list of state codes is contained in the Federal Information Processing Standards (FIPS) Publication 5-1, "States and Outlying Areas of the United States," dated 1970; and a complete list of city and place codes is contained in the Federal Information Processing Standards (FIPS) Publication 55. "Codes for Named Populated Places and Related Entities of the State of the United States," dated 1978.

\section{GENERAL DESCRIPTION:}

This field is used to retrieve addresses of operating offices from the WDSD database. The code for an office is unique within an organization but is not necessarily unique across the database. Its counterpart in the MWDI database is component number 17, WDSD_OFC_CODE. 
FIELD NAME:

IN DATABASE FILE:

MANDATORY:

DATA TYPE:

LARGEST OR LONGEST VALUE:

\section{O_NUSCNTRY}

WDOFCSD

No

Character

2 characters

\section{DATA VALUES:}

This field contains a FIPS country code only if the office has data for sites physically located outside the United States; if the office's data is for sites within the United States, the field has no value.

A complete list of country codes is contained in the Federal Information Processing Standards (FIPS) Publication 10-2, "Countries, Dependencies, and Areas of Special Sovereignty," dated 1976.

\section{GENERAL DESCRIPTION:}

The non-United States country code is valued for only those offices that have data from sites that lie outside of the borders of the United States and its outlying areas. It bears no relationship to the location of the office. 
FIELD NAME:

IN DATABASE FILE:

MANDATORY:

DATA TYPE:

LARGEST OR LONGEST VALUE:
OFC_STATE

WDOFCSD

No

Numeric

\section{DATA VALUES:}

This field contains a code representing the state or outlying area for which the office has data.

\section{GENERAL DESCRIPTION:}

State codes are contained in the Federal Information Processing Standards (FIPS) Publication 5-1, "States and Outlying Areas of the United States," dated June 15, 1970. The NAWDEX Program Office assigns temporary codes to identify foreign installations. The state code represents the location of a data collection site for which the office has data, and not the location of the office. 
FIELD NAME:

IN DATABASE FILE:

MANDATORY:

DATA TYPE:

LARGEST OR LONGEST VALUE:
O_DAT_DIR

WDOFCSD

Yes

Character

10 characters

\section{DATA VALUES:}

Code Meaning
W
Water Data Sources Directory
R
Water-related Data Sources Directory
O Directory of Water Resources Organizations

\section{GENERAL DESCRIPTION:}

The O_DAT_DIR field contains a combination of 1 to 10 codes, left-justified, used in retrieving specified types of directories. Each code may occur only once in this field. The NAWDEX Program Office will add codes, as the need arises, to meet future directory needs. 
DATABASE FILE NAME:

DATABASE FILE DEFINITION:

FIELDS:
WDOCNTY

Information about the counties for which the office has data

NWDX AGCY

OFC_CODE

OFC-STATE

OFC_CNTY 
FIELD NAME:

IN DATABASE FILE:

MANDATORY:

DATA TYPE:

LARGEST OR LONGEST VALUE:
NWDX_AGCY

WDOCNTY (Also in WDORG)

Yes

Character

5 characters

DATA VALUES:

The NAWDEX agency code varies in length from three to five characters. For federal organizations, it is US followed by a two- or three-character abbreviation of the organization's name. Values for non-federal organizations whose activities are within a given state boundary have a two-character state code followed by a NAWDEX-assigned sequence number. Values for non-federal organizations having activities at the multistate or national level have a three-to five-character abbreviation of the organization name (the characters US will not appear in the first two character positions). Alphabetic state codes are contained in the Federal Information Processing Standards (FIPS) Publication 5-1, dated June 15, 1970, "States and Outlying Areas of the United States." NAWDEX agency codes are presented in the publication, "Identification Codes for Organizations Listed in Computerized Data Systems of the U.S. Geological Survey" which may be obtained from the National Water Data Exchange, U.S. Geological Survey, 421 National Center, Reston, Virginia 22092. Telephone: (703) 648-6848; FTS 959-6848.

\section{GENERAL DESCRIPTION:}

The NAWDEX agency code is assigned by the NAWDEX Program Office and is the unique identifier for participating federal and non-federal organizations that actively collect and store water data. Non-federal organizations include state, county, and municipal agencies, as well as intergovernmental compacts, private organizations, universities, and any local organizations at other than county or municipal level. 
FIELD NAME:

IN DATABASE FILE:

MANDATORY:

DATA TYPE:

LARGEST OR LONGEST VALUE: 9 characters
OFC_CODE

WDOCNTY (Also in WDOFCO)

Yes

Character

\section{DATA VALUES:}

The NAWDEX Program Office assigns the OFC_CODE field. The first two characters of the code consists of two digits representing the state or two letters representing the country in which the office is located; the next five characters consist of five digits representing the city or place in which the office is located; and the last two characters consist of an arbitrary two-digit sequence number to uniquely identify multiple offices within the same city or place. A complete list of country codes is contained in the Federal Information Processing Standards (FIPS) Publication 10-2, "Countries, Dependencies, and Areas of Special Sovereignty," dated 1976; a complete list of state codes is contained in the Federal Information Processing Standards (FIPS) Publication 5-1, "States and Outlying Areas of the United States," dated 1970; and a complete list of city and place codes is contained in the Federal Information Processing Standards (FIPS) Publication 55, "Codes for Named Populated Places and Related Entities of the State of the United States," date 1978.

\section{GENERAL DESCRIPTION:}

This field is used to retrieve addresses of operating offices from the WDSD database. The code for an office is unique within an organization but is not necessarily unique across the database. Its counterpart in the MWDI database is component number 17 , WDSD_OFC_CODE. 
FIELD NAME:

IN DATABASE FILE:

MANDATORY:

DATA TYPE:

LARGEST OR LONGEST VALUE:
OFC_STATE

WDOCNTY (Also in WDOFCSD)

No

Numeric

99

\section{DATA VALUES:}

This field contains a code representing the state or outlying area for which the office has data.

\section{GENERAL DESCRIPTION:}

State codes are contained in the Federal Information Processing Standards (FIPS) Publication 5-1, "States and Outlying Areas of the United States," dated June 15, 1970. The NAWDEX Program Office assigns temporary codes to identify foreign installations. The state code represents the location of a data collection site for which the office has data, and not the location of the office. 
FIELD NAME:

IN DATABASE FILE:

MANDATORY:

DATA TYPE:

LARGEST OR LONGEST VALUE:
OFC_CNTY

\section{WDOCNTY}

Yes

Numeric

840

\section{DATA VALUES:}

This field contains a three-digit code for a county for which the office has data. For data from sites outside the United States, this field has no value.

\section{GENERAL DESCRIPTION:}

This field contains a code representing a county in which a data collection site exists and for which the office holds data. The county must be in the state whose code is in the OFC_STATE field. County codes are contained in the Federal Information Processing Standards (FIPS) Publication 6-3, "Counties and County Equivalents of the States of the United States and the District of Columbia," dated December 15, 1979.

Note: Codes used to value this field include independent city codes for the States of Maryland, Missouri, Nevada, and Virginia; division codes for the State of Alaska; and county equivalents of Puerto Rico and the Virgin Islands. 
DATABASE FILE NAME:

DATABASE FILE DEFINITION:

FIELDS:
WDOCOM

General information about an office and its data holdings

NWDX_AGCY

OFC CŌDE

OCOM 
FIELD NAME:

IN DATABASE FILE:

MANDATORY:

DATA TYPE:

LARGEST OR LONGEST VALUE: 5 characters
NWDX_AGCY

WDOCOM (Also in WDORG)

Yes

Character

\section{DATA VALUES:}

The NAWDEX agency code varies in length from three to five characters. For federal organizations, it is US followed by a two- or three-character abbreviation of the organization's name. Values for non-federal organizations whose activities are within a given state boundary have a two-character state code followed by a NAWDEX-assigned sequence number. Values for non-federal organizations having activities at the multistate or national level have a three-to five-character abbreviation of the organization name (the characters US will not appear in the first two character positions). Alphabetic state codes are contained in the Federal Information Processing Standards (FIPS) Publication 5-1, dated June 15, 1970, "States and Outlying Areas of the United States." NAWDEX agency codes are presented in the publication, "Identification Codes for Organizations Listed in Computerized Data Systems of the U.S. Geological Survey" which may be obtained from the National Water Data Exchange, U.S. Geological Survey, 421 National Center, Reston, Virginia 22092. Telephone: (703) 648-6848; FTS 959-6848.

\section{GENERAL DESCRIPTION:}

The NAWDEX agency code is assigned by the NAWDEX Program Office and is the unique identifier for participating federal and non-federal organizations that actively collect and store water data. Non-federal organizations include state, county, and municipal agencies, as well as intergovernmental compacts, private organizations, universities, and any local organizations at other than county or municipal level. 
FIELD NAME:

IN DATABASE FILE:

MANDATORY:

DATA TYPE:

LARGEST OR LONGEST VALUE:
OFC_CODE

WDOCOM (Also in WDOFCO)

Yes

Character

9 characters

\section{DATA VALUES:}

The NAWDEX Program Office assigns the OFC_CODE field. The first two characters of the code consists of two digits representing the state or two letters representing the country in which the office is located; the next five characters consist of five digits representing the city or place in which the office is located; and the last two characters consist of an arbitrary two-digit sequence number to uniquely identify multiple offices within the same city or place. A complete list of country codes is contained in the Federal Information Processing Standards (FIPS) Publication 10-2, "Countries, Dependencies, and Areas of Special Sovereignty," dated 1976; a complete list of state codes is contained in the Federal Information Processing Standards (FIPS) Publication 5-1, "States and Outlying Areas of the United States," dated 1970; and a complete list of city and place codes is contained in the Federal Information Processing Standards (FIPS) Publication 55, "Codes for Named Populated Places and Related Entities of the State of the United States," dated 1978.

\section{GENERAL DESCRIPTION:}

This field is used to retrieve addresses of operating offices from the WDSD database. The code for an office is unique within an organization but is not necessarily unique across the database. Its counterpart in the MWDI database is component number 17 , WDSD_OFC_CODE. 
FIELD NAME:

IN DATABASE FILE:

MANDATORY:

DATA TYPE:

LARGEST OR LONGEST VALUE:

DATA VALUES:
COM

WDOCOM

No

Character

65 characters

This field contains comments about the office and its data holdings. Up to fifteen comment lines are allowed.

GENERAL DESCRIPTION:

The purpose of this field is to provide a means of storing general information about an office and its data holdings. The information may include anything that would interest a user of NAWDEX.

60 
DATABASE FILE NAME:

DATABASE FILE DEFINITION:

FIELDS:
WDOSD

Information about the number and types of sites operated by the organization

NWDX_AGCY
NUS_CNTRY
STATE
SW_QLTY
SW_QNTY
GW_QLTY
GW_LVL
GW_PUMP
GLGC
WTR_USE
MET_DAT
DAT_DIR


FIELD NAME:

IN DATABASE FILE:

MANDATORY:

DATA TYPE:

LARGEST OR LONGEST VALUE:
NWDX_AGCY

WDOSD (Also in WDORG)

Yes

Character

5 characters

\section{DATA VALUES:}

The NAWDEX agency code varies in length from three to five characters. For federal organizations, it is US followed by a two-or three-character abbreviation of the organization's name. Values for non-federal organizations whose activities are within a given state boundary have a two-character state code followed by a NAWDEX-assigned sequence number. Values for non-federal organizations having activities at the multistate or national level have a three-to five-character abbreviation of the organization name (the characters US will not appear in the first two character positions). Alphabetic state codes are contained in the Federal Information Processing Standards (FIPS) Publication 5-1, dated June 15, 1970, "States and Outlying Areas of the United States." NAWDEX agency codes are presented in the publication, "Identification Codes for Organizations Listed in Computerized Data Systems of the U.S. Geological Survey" which may be obtained from the National Water Data Exchange, U.S. Geological Survey, 421 National Center, Reston, Virginia 22092. Telephone: (703) 648-6848; FTS 959-6848.

\section{GENERAL DESCRIPTION:}

The NAWDEX agency code is assigned by the NAWDEX Program Office and is the unique identifier for participating federal and non-federal organizations that actively collect and store water data. Non-federal organizations include state, county, and municipal agencies, as well as intergovernmental compacts, private organizations, universities, and any local organizations at other than county or municipal level. 
FIELD NAME:

NUS_CNTRY

IN DATABASE FILE:

WDOSD

MANDATORY:

No

DATA TYPE:

Character

LARGEST OR LONGEST VALUE: 2 characters

DATA VALUES:

This field contains a country code only if the organization operates data collection sites physically located outside the United States. If the organization's data collection sites are within the United States, the field has no value.

A complete list of country codes is contained in the Federal Information Processing Standards (FIPS) Publication 10-2, "Countries, Dependencies, and Areas of Special Sovereignty," dated 1976.

\section{GENERAL DESCRIPTION:}

The non-United States country code has a value for only those organizations that operate data collection sites that lie outside of the borders of the United States and its outlying areas. It bears no relationship to the location of the organization. 
FIELD NAME:

IN DATABASE FILE:

MANDATORY:

DATA TYPE:

LARGEST OR LONGEST VALUE:
STATE

WDOSD

No

Numeric

\section{DATA VALUES:}

This field contains a code representing the state or outlying area in which the organization operates data collection sites. A complete list of state or outlying area codes is contained in the Federal Information Processing Standards (FIPS) Publication 5-1, "States and Outlying Areas of the United States," dated June 15, 1970.

\section{GENERAL DESCRIPTION:}

The STATE field has a value for those states or outlying areas in which there are sites for which the organization has data. It bears no relationship to the location of the organization. 
FIELD NAME:

SW_QLTY

IN DATABASE FILE:

WDOSD

MANDATORY:

No

DATA TYPE:

Numeric

LARGEST OR LONGEST VALUE: 9999999

DATA VALUES:

This field contains the total number of surface-water-quality sites, located in the state identified by the STATE field or the country identified by the NUS_CNTRY field which the organization operates.

\section{GENERAL DESCRIPTION:}

The total includes surface-water sites at which one or more water-quality parameters are, or have been, collected. It includes both active and inactive sites and it makes no difference whether or not the organization supplies the data upon request. Sites included in the total are only those that are operated by the organization in the state identified by STATE or the country identified by NUS_CNTRY. Water-quality parameters include physical, chemical, sediment, or biological characteristics of water. 
FIELD NAME:

IN DATABASE FILE:

MANDATORY:

DATA TYPE:

LARGEST OR LONGEST VALUE:
SW_QNTY

WDOSD

No

Numeric

9999999

\section{DATA VALUES:}

This field contains the total number of surface-water-quantity sites, located in the state identified by the STATE field or the country identified by the NUS_CNTRY field, which the organization operates.

\section{GENERAL DESCRIPTION:}

The total includes surface-water sites at which one or more water-quantity parameters are, or have been, collected. It includes both active and inactive sites and it makes no difference whether or not the organization supplies the data upon request. Sites included in the total are only those that are operated by the organization in the state identified by STATE or the country identified by NUS_CNTRY. Surface-water-quantity parameters include such items as stream fiow, peak fiow, low flow, peak stage, low stage, reservoir content, and change in reservoir content. 
FIELD NAME:

IN DATABASE FILE:

MANDATORY:

DATA TYPE:

LARGEST OR LONGEST VALUE:
GW_QLTY

WDOSD

No

Numeric

9999999

\section{DATA VALUES:}

This field the total number of ground-water-quality sites, located in the state identified by the STATE field or the country identified by the NUS_CNTRY field, which the organization operates.

\section{GENERAL DESCRIPTION:}

The total includes ground-water sites at which one or more water quality parameters are, or have been, collected. It includes both active and inactive sites and it makes no difference whether or not the organization supplies the data upon request. Sites included in the total are only those that are operated by the organization in the state identified by the STATE field or the country identified by the NUS_CNTRY field. Water quality parameters include physical, chemical, or biological characteristics of water. 
FIELD NAME:

GW_LVL

IN DATABASE FILE:

WDOSD

MANDATORY:

No

DATA TYPE:

Numeric

LARGEST OR LONGEST VALUE: 9999999

DATA VALUES:

This field contains the total number of data-monitoring sites the organization operates, at which water-level measurements are made in the state identified by the STATE field or the country identified by NUS_CNTRY field.

\section{GENERAL DESCRIPTION:}

The total includes ground-water sites at which water level measurements are, or have been, collected. It includes both active and inactive sites and it makes no difference whether or not the organization supplies the data upon request. Sites included in the total are only those that are operated by the organization in the state identified by the STATE field or the country identified by the NUS_CNTRY field. 
FIELD NAME:

IN DATABASE FILE:

MANDATORY:

DATA TYPE:

LARGEST OR LONGEST VALUE:
GW_PUMP

WDOSD

No

Numeric

9999999

\section{DATA VALUES:}

This field contains the total number of data-monitoring sites, at which there is ground-water pumpage, located in the state identified by the STATE field or the country identified by the NUS_CNTRY field, which the organization operates.

\section{GENERAL DESCRIPTION:}

The total includes ground-water sites at which pumpage measurements are, or have been, collected. It includes both active and inactive sites and it makes no difference whether or not the organization supplies the data upon request. Sites included in the total are only those that are operated by the organization in the state identified by the STATE field or the country identified by the NUS_CNTRY field. 
FIELD NAME:

IN DATABASE FILE:

MANDATORY:

DATA TYPE:

LARGEST OR LONGEST VALUE:
GLGC

WDOSD

No

Numeric

9999999

\section{DATA VALUES:}

This field contains the total number of ground-water sites with geologic descriptions available, located in the state identified by the STATE field or the country identified by the NUS_CNTRY field which the organization operates.

\section{GENERAL DESCRIPTION:}

The total includes ground-water sites for which there is information describing the geology in which the site is located. This includes descriptions of the surficial geology and other information such as stratigraphic or lithologic logs. It includes both active and inactive sites and it makes no difference whether or not the organization supplies the information upon request. Sites included in the total are only those that are operated by the organization in the state identified by the STATE field or the country identified by the NUS_CNTRY field. 
FIELD NAME:

IN DATABASE FILE:

MANDATORY:

DATA TYPE:

LARGEST OR LONGEST VALUE:
WTR_USE

WDOSD

No

Numeric

\section{DATA VALUES:}

This field contains the total number of sites or locations at which water-use data are being collected or monitored by the organization in the state identified by the STATE field or the country identified by the NUS_CNTRY field.

\section{GENERAL DESCRIPTION:}

The total includes all sites or locations at which water-use data are, or have been, collected or monitored. It includes both active and inactive sites or locations and it makes no difference whether or not the organization supplies the data upon request. Sites or locations included in the total are only those that are operated by the organization in the state identified by the STATE field or the country identified by the NUS_CNTRY field. Water-use data includes all data and information collected about the use of water, both withdrawals and returns, for agriculture, industry, municipal water supplies, domestic use, energy production and development, mining, and a variety of other purposes. 
FIELD NAME:

MET_DAT

IN DATABASE FILE:

WDOSD

MANDATORY:

No

DATA TYPE:

Numeric

LARGEST OR LONGEST VALUE: $\quad 9999999$

\section{DATA VALUES:}

This field contains the total number of sites at which meteorological data are measured or monitored by the organization in the state identified by the STATE field or the country identified by the NUS_CNTRY field.

\section{GENERAL DESCRIPTION:}

The total includes all sites at which meteorological data are, or have been, collected or monitored. It includes both active and inactive sites and it makes no difference whether or not the organization supplies the data upon request. Sites included in the total are only those that are operated by the organization in the state identified by the STATE field or the country identified by the NUS_CNTRY field. Meteorological data include measurements of precipitation, snow accumulations, wind direction and velocity, temperature, and relative humidity. 
FIELD NAME:

IN DATABASE FILE:

MANDATORY:

DATA TYPE:

LARGEST OR LONGEST VALUE:
DAT_DIR

WDOSD

Yes

Character

10 characters

\section{DATA VALUES:}

Code Meaning
W Water Data Sources Directory
R Water-related Data Sources Directory
O Directory of Water Resources Organizations

\section{GENERAL DESCRIPTION:}

This field contains a combination of 1 to 10 codes, left-justified, used in retrieving specified types of directories. Each code may occur only once in this field. The NAWDEX Program Office will add codes, as the need arises, to meet future directory needs. 
DATABASE FILE NAME:

DATABASE FILE DEFINITION:

FIELDS:
WDCNTY

Identifies the counties in which the organization operates data collection sites

NWDX_AGCY

STATE

COUNTY 
FIELD NAME:

IN DATABASE FILE:

MANDATORY:

DATA TYPE:

LARGEST OR LONGEST VALUE:
NWDX_AGCY

WDCNTY (Also in WDORG)

Yes

Character

5 characters

\section{DATA VALUES:}

The NAWDEX agency code varies in length from three to five characters. For federal organizations, it is US followed by a two- or three-character abbreviation of the organization's name. Values for non-federal organizations whose activities are within a given state boundary have a two-character state code followed by a NAWDEX-assigned sequence number. Values for non-federal organizations having activities at the multistate or national level have a three-to five-character abbreviation of the organization name (the characters US will not appear in the first two character positions). Alphabetic state codes are contained in the Federal Information Processing Standards (FIPS) Publication 5-1, dated June 15, 1970, "States and Outlying Areas of the United States." NAWDEX agency codes are presented in the publication, "Identification Codes for Organizations Listed in Computerized Data Systems of the U.S. Geological Survey" which may be obtained from the National Water Data Exchange, U.S. Geological Survey, 421 National Center, Reston, Virginia 22092. Telephone: (703) 648-6848; FTS 959-6848.

\section{GENERAL DESCRIPTION:}

The NAWDEX agency code is assigned by the NAWDEX Program Office and is the unique identifier for participating federal and non-federal organizations that actively collect and store water data. Non-federal organizations include state, county, and municipal agencies, as well as intergovernmental compacts, private organizations, universities, and any local organizations at other than county or municipal level. 
FIELD NAME:

IN DATABASE FILE:

MANDATORY:

DATA TYPE:

LARGEST OR LONGEST VALUE:
STATE

WDCNTY (Also in WDOSD)

No

Numeric

99

\section{DATA VALUES:}

This field contains a code representing the state or outlying area in which the organization operates data collection sites. A complete list of state or outlying area codes is contained in the Federal Information Processing Standards (FIPS) Publication 5-1, "States and Outlying Areas of the United States," dated June 15, 1970.

\section{GENERAL DESCRIPTION:}

The STATE field has a value for those states or outlying areas in which there are sites for which the organization has data. It bears no relationship to the location of the organization. 
FIELD NAME:

COUNTY

IN DATABASE FILE:

WDCNTY

MANDATORY:

Yes

DATA TYPE:

Numeric

LARGEST OR LONGEST VALUE: $\quad 840$

DATA VALUES:

This field contains a code for a county in which the organization operates one or more data collection sites. For sites operated outside the United States, there will be no occurrences in WDCNTY.

\section{GENERAL DESCRIPTION:}

This field has a value for those counties in which there are one or more data collection sites operated by the organization. The counties must be in the state identified in the STATE field. A complete list of county codes is contained in the Federal Information Processing Standards (FIPS) Publication 6-3, "Counties and County Equivalents of the States of the United States and the District of Columbia," dated December 15, 1979.

Note: Codes used to value this field include independent city codes for the States of Maryland, Missouri, Nevada, and Virginia; division codes for the State of Alaska; and county equivalent codes for American Samoa, Guam, Puerto Rico, and the Virgin Islands. 
DATABASE FILE NAME:

DATABASE FILE DEFINITION:

FIELDS:
WDOS

Information about other sources of the organization's data. If another organization stores in part or in whole, data available from the organization named in the ORG_NAME field, and will respond to requests for the data, that organization is an "other source."

NWDX AGCY

OS_ALT

OS_AGCY

OS NAME

OS_CONTAC

OS_ST

OS_CITY

OS_STATE

OS_ZIP

OS CNTRY

OS_PHONE

OS_DIR

OS-DAT

OS_MEDIA 
FIELD NAME:

IN DATABASE FILE:

MANDATORY:

DATA TYPE:

LARGEST OR LONGEST VALUE: 5 characters
NWDX_AGCY

WDOS (Also in WDORG)

Yes

Character

\section{DATA VALUES:}

The NAWDEX agency code varies in length from three to five characters. For federal organizations, it is US followed by a two- or three-character abbreviation of the organization's name. Values for non-federal organizations whose activities are within a given state boundary have a two-character state code followed by a NAWDEX-assigned sequence number. Values for non-federal organizations having activities at the multistate or national level have a three-to five-character abbreviation of the organization name (the characters US will not appear in the first two character positions). Alphabetic state codes are contained in the Federal Information Processing Standards (FIPS) Publication 5-1, dated June 15, 1970, "States and Outlying Areas of the United States." NAWDEX agency codes are presented in the publication, "Identification Codes for Organizations Listed in Computerized Data Systems of the U.S. Geological Survey" which may be obtained from the National Water Data Exchange, U.S. Geological Survey, 421 National Center, Reston, Virginia 22092. Telephone: (703) 648-6848; FTS 959-6848.

\section{GENERAL DESCRIPTION:}

The NAWDEX agency code is assigned by the NAWDEX Program Office and is the unique identifier for participating federal and non-federal organizations that actively collect and store water data. Non-federal organizations include state, county, and municipal agencies, as well as intergovernmental compacts, private organizations, universities, and any local organizations at other than county or municipal level. 
FIELD NAME:

IN DATABASE FILE:

MANDATORY:

DATA TYPE:

LARGEST OR LONGEST VALUE: A or $P$
OS_ALT

WDOS

Yes

Character

\section{DATA VALUES:}

This field contains either an " $\mathrm{A}$ " or a "P" depending whether the organization is an alternative source or a preferred source, respectively.

\section{GENERAL DESCRIPTION:}

An alternative data source is an "other source" which can be contacted instead of the organization that collected the data. A preferred data source is an "other source" which should be contacted instead of the collector organization. A collector organization that does not have the capability to respond to requests for data may appoint another organization as a preferred source. If the collector organization will respond to requests for its data, and its data is also available from another organization, that other organization may be appointed as an alternative source.

All data stored by the collector organization may not be available from the "other source" organization. The OS_DAT field shows what kinds of data are available from the "other source" organization, and any further qualifications can be explained in comment form in WDOSCOM. 
FIELD NAME:

IN DATABASE FILE:

MANDATORY:

DATA TYPE:

LARGEST OR LONGEST VALUE: 5 characters
OS_AGCY

WDOS

Yes

Character

\section{DATA VALUes:}

This field contains the NAWDEX agency code for the other source organization. The NAWDEX agency code varies in length from three to five characters. For federal organizations it is US followed by a meaningful two- or three-character abbreviation of the organization name. Values for non-federal organizations whose activities are contained within a given state boundary will have a two-character state code followed by a NAWDEX assigned sequence number. Values for non-federal organizations having activities at the multistate or national level have a meaningful three- to five-character abbreviation of the organization name (the letters US will not appear in the first two positions). Alphabetic state codes are contained in the Federal Information Processing Standards (FIPS) Publication 5-1, "States and Outlying Areas of the United States," dated June 15, 1970. NAWDEX agency codes are presented in the publication "Identification Codes for Organizations Listed in Computerized Data Systems of the U.S. Geological Survey," which may be obtained from the National Water Data Exchange, U.S. Geological Survey, 421 National Center, Reston, Virginia 22092.

\section{GENERAL DESCRIPTION:}

The NAWDEX Program Office assigns the NAWDEX agency code. This code is the unique identifier for the participating federal and non-federal organizations that actively collect and store water data. Non-federal organizations include state, county, and municipal agencies, as well as intergovernmental compacts, private organizations, universities, and any local organizations at other than county or municipal level. 
FIELD NAME:

IN DATABASE FILE:

MANDATORY:

DATA TYPE:

LARGEST OR LONGEST VALUE:

DATA VALUES:

This field contains up to $\mathbf{4 0}$ characters.

GENERAL DESCRIPTION:

This field contains the official name of the organization.

82 
FIELD NAME:

IN DATABASE FILE:

MANDATORY:

DATA TYPE:

LARGEST OR LONGEST VALUE:

DATA VALUES:

This field contains up to 40 characters.

GENERAL DESCRIPTION:

The contact is the name, or title, of the person or organization, that should be contacted by a requester for obtaining the organization's data that are indexed in NAWDEX.

83 
FIELD NAME:

IN DATABASE FILE:

MANDATORY:

DATA TYPE:

LARGEST OR LONGEST VALUE:

DATA VALUES:

This field contains up to $\mathbf{4 0}$ characters.

GENERAL DESCRIPTION:

This field contains the street address or post office box number of the contact named in the OS_CONTAC field. It is the address to which a requester should send a letter asking for the organization's data indexed in NAWDEX.

84 
FIELD NAME:

OS_CITY

IN DATABASE FILE:

WDOS

MANDATORY:

No

DATA TYPE:

Character

LARGEST OR LONGEST VALUE: 30 characters

DATA VALUES:

This field contains up to 30 characters.

\section{GENERAL DESCRIPTION:}

This field contains the city in which the organization is located. The city name accompanies the address and, therefore, should be the name of the city used for mailing. 
FIELD NAME:

IN DATABASE FILE:

MANDATORY:

DATA TYPE:

LARGEST OR LONGEST VALUE:
OS_STATE

WDOS

No

Character

\section{DATA VALUES:}

This field contains a postal code identifying the state in which the organization is located.

\section{GENERAL DESCRIPTION:}

Postal codes are alphabetic state abbreviations recognized by the U.S. Postal Service as part of a mailing address. The OS_STATE field has a value only if the organization is located within the United States or one of its territories. If the organization is outside the United States, this field has no value. 
FIELD NAME:

OS_ZIP

IN DATABASE FILE:

WDOS

MANDATORY:

No

DATA TYPE:

Character

LARGEST OR LONGEST VALUE:

9999999999

DATA VALUES:

This field contains up to ten digits and/or characters which is the U.S. Postal ZIP code or foreign postal code of the organization.

\section{GENERAL DESCRIPTION:}

The ZIP code is a geographic code that identifies areas within the United States and its possessions for simplifying the distribution of mail by the U.S. Postal Service. The ZIP code alinements do not adhere to boundaries of cities, counties, states, or other jurisdictions. For organizations outside the United States and its territories, the foreign postal code, if applicable, has a value in the format of its local usage. 
FIELD NAME:

OS_CNTRY

IN DATABASE FILE:

WDOS

MANDATORY:

No

DATA TYPE:

Character

LARGEST OR LONGEST VALUE: 30 characters

DATA VALUES:

This field contains the name of the country in which the organization is located. If the organization is in the United States, use "USA" for an abbreviation. For non-United States countries, store the full name of the country in this field.

\section{GENERAL DESCRIPTION:}

The name of the country applies to the country in which the organization is physically located. It is the name that would be part of a mailing address on correspondence addressed to the organization. It bears no relationship to the data holdings of the organization. 
FIELD NAME:

OS_PHONE

IN DATABASE FILE:

WDOS

MANDATORY:

No

DATA TYPE:

Character

LARGEST OR LONGEST VALUE: $\quad 999-999-9999$

DATA VALUES:

This field contains the telephone number of the contact named in the OS_CONTAC field. If the office is within the United States or one of its territories, the number consists of a three-digit area code, followed by a dash, and followed by the seven digits of the local telephone number. A dash appears between the third and fourth digits of the local number. If the office is outside the United States, store the correct telephone number in whatever format required.

\section{GENERAL DESCRIPTION:}

This field contains the telephone number to call the office and its contact. 
FIELD NAME:

IN DATABASE FILE:

MANDATORY:

DATA TYPE:

LARGEST OR LONGEST VALUE:
OS_DIR

WDOS

Yes

Character

10 characters

\section{DATA VALUES:}

Code Meaning
W Water Data Sources Directory
R Water-related Data Sources Directory
O Directory of Water Resources Organizations

\section{GENERAL DESCRIPTION:}

The OS_DIR field contains a combination of 1 to 10 codes, left-justified, used in retrieving specified types of directories. Each code may occur only once in this field. The NAWDEX Program Office will add codes, as the need arises, to meet future directory needs. 
FIELD NAME:

OS_DAT

IN DATABASE FILE:

WDOS

MANDATORY:

Yes

DATA TYPE:

Character

LARGEST OR LONGEST VALUE: 6 characters

DATA VALUES:

This field contains one or more alphabetic codes showing what kinds of data from the collector organization are available from the "other source" organization. Use one to six codes.

GENERAL DESCRIPTION:

Code Meaning

D Geologic Descriptions - Information describing the geology of the area around data collection sites is available.

G Ground Water Quality - Water quality data from ground-water sites are available.

L Ground Water Level - Water-level measurements from ground-water sites are available.

P Ground Water Pumpage - Pumpage measurements (drawdown volume) from ground-water sites are available.

Q Surface Water Quantity - Water-quantity data from surface-water sites are available.

S Surface Water Quality Stations - Water-quality data from surface-water sites are available. 
FIELD NAME:

IN DATABASE FILE:

MANDATORY:

DATA TYPE:

LARGEST OR LONGEST VALUE:
OS MEDIA

WDOS

No

Character

\section{DATA VALUES:}

This field contains a code that describes the type(s) of media used to store the organization's hydrologic data.

\section{GENERAL DESCRIPTION:}

Code Meaning

C Computer recognizable - The data are stored on media that can be read by a computer. This might be punched cards, paper tape, magnetic tape, magnetic disk, drum, or some similar device.

D Computer and published - Data are stored in both computer recognizable and published form.

E Computer and microform - Data are stored in both computer recognizable and microform formats.

F Computer, published, and microform - Data are stored in computer recognizable, published, and microform formats.

G Published and microform - Data are stored in both published and microform formats.

M

Microform - Printed data which are stored in reduced size on roll microfilm, microfiche, aperture cards, or some other type of microfilm.

P Published - The data are available in printed form. 
DATABASE FILE NAME:

DATABASE FILE DEFINITION:

FIELDS:

\section{WDOSCOM}

General information about an "other source" organization and its data holdings

NWDX AGCY

OS $A \bar{C} C Y$

OSC̄OM 
FIELD NAME:

IN DATABASE FILE:

MANDATORY:

DATA TYPE:

LARGEST OR LONGEST VALUE: 5 characters
NWDX_AGCY

WDOSCOM (Also in WDORG)

Yes

Character

\section{DATA VALUES:}

The NAWDEX agency code varies in length from three to five characters. For federal organizations, it is US followed by a two- or three-character abbreviation of the organization's name. Values for non-federal organizations whose activities are within a given state boundary have a two-character state code followed by a NAWDEX-assigned sequence number. Values for non-federal organizations having activities at the multistate or national level have a three-to five-character abbreviation of the organization name (the characters US will not appear in the first two character positions). Alphabetic state codes are contained in the Federal Information Processing Standards (FIPS) Publication 5-1, dated June 15, 1970, "States and Outlying Areas of the United States." NAWDEX agency codes are presented in the publication, "Identification Codes for Organizations Listed in Computerized Data Systems of the U.S. Geological Survey" which may be obtained from the National Water Data Exchange, U.S. Geological Survey, 421 National Center, Reston, Virginia 22092. Telephone: (703) 648-6848; FTS 959-6848.

\section{GENERAL DESCRIPTION:}

The NAWDEX agency code is assigned by the NAWDEX Program Office and is the unique identifier for participating federal and non-federal organizations that actively collect and store water data. Non-federal organizations include state, county, and municipal agencies, as well as intergovernmental compacts, private organizations, universities, and any local organizations at other than county or municipal level. 
FIELD NAME:

IN DATABASE FILE:

MANDATORY:

DATA TYPE:

LARGEST OR LONGEST VALUE: 5 characters
OS_AGCY

WDOSCOM (Also in WDOS)

Yes

Character

\section{DATA VALUES:}

This is the NAWDEX agency code for the other source organization. The NAWDEX agency code varies in length from three to five characters. For federal organizations it is US followed by a meaningful two- or three-character abbreviation of the organization name. Values for non-federal organizations whose activities are contained within a given state boundary will have a two-character state code followed by a NAWDEX assigned sequence number. Values for non-federal organizations having activities at the multistate or national level have a meaningful three-to five-character abbreviation of the organization name (the letters US will not appear in the first two positions). Alphabetic state codes are contained in the Federal Information Processing Standards (FIPS) Publication 5-1, "States and Outlying Areas of the United States," dated June 15, 1970. NAWDEX agency codes are presented in the publication "Identification Codes for Organizations Listed in Computerized Data Systems of the U.S. Geological Survey," which may be obtained from the National Water Data Exchange, U.S. Geological Survey, 421 National Center, Reston, Virginia 22092.

\section{GENERAL DESCRIPTION:}

The NAWDEX Program Office assigns the NAWDEX agency code. The agency code is the unique identifier for the participating federal and non-federal organizations that actively collect and store water data. Non-federal organizations include state, county, and municipal agencies, as well as intergovernmental compacts, private organizations, universities, and any local organizations at other than county or municipal level. 
FIELD NAME:

IN DATABASE FILE:

MANDATORY:

DATA TYPE:

LARGEST OR LONGEST VALUE:
OSCOM

WDOSCOM

Yes

Character

40 characters

DATA VALUES:

This field consists of up to 10 comment lines about the other source organization and its data holdings.

\section{GENERAL DESCRIPTION:}

The purpose of this field is to provide a means of storing general information about an "other source" organization and its data holdings. The information may include anything that would potentially be of interest to a user of NAWDEX. 
DATABASE FILE NAME:

DATABASE FILE DEFINITION:

FIELDS:
WDMLO

Information about individuals within the organization that should be consulted on waterdata acquisition, coordination, and indexing activities. Information may also be provided about individuals that serve as liaison officials in other water-related matters as the need arises.

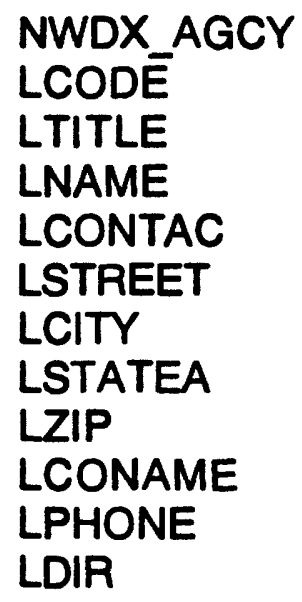

97 
FIELD NAME:

IN DATABASE FILE:

MANDATORY:

DATA TYPE:

LARGEST OR LONGEST VALUE: 5 characters
NWDX_AGCY

WDMLO (Also in WDORG)

Yes

Character

\section{DATA VALUES:}

The NAWDEX agency code varies in length from three to five characters. For federal organizations, it is US followed by a two- or three-character abbreviation of the organization's name. Values for non-federal organizations whose activities are within a given state boundary have a two-character state code followed by a NAWDEX-assigned sequence number. Values for non-federal organizations having activities at the multistate or national level have a three-to five-character abbreviation of the organization name (the characters US will not appear in the first two character positions). Alphabetic state codes are contained in the Federal Information Processing Standards (FIPS) Publication 5-1, dated June 15, 1970, "States and Outlying Areas of the United States." NAWDEX agency codes are presented in the publication, "Identification Codes for Organizations Listed in Computerized Data Systems of the U.S. Geological Survey" which may be obtained from the National Water Data Exchange, U.S. Geological Survey, 421 National Center, Reston, Virginia 22092. Telephone: (703) 648-6848; FTS 959-6848.

\section{GENERAL DESCRIPTION:}

The NAWDEX agency code is assigned by the NAWDEX Program Office and is the unique identifier for participating federal and non-federal organizations that actively collect and store water data. Non-federal organizations include state, county, and municipal agencies, as well as intergovernmental compacts, private organizations, universities, and any local organizations at other than county or municipal level. 
FIELD NAME:

IN DATABASE FILE:

MANDATORY:

DATA TYPE:

LARGEST OR LONGEST VALUE: 9 characters
LCODE

WDMLO

Yes

Character

\section{DATA VALUES:}

The NAWDEX Program Office assigns the liaison office code which consists of a 9character code. The first two characters of the code consists of two digits representing the state or two letters representing the country in which the office is located; the next five characters consist of five digits representing the city or place in which the office is located; and the next two characters consist of an arbitrary two-digit sequence number to uniquely identify multiple offices within the same city or place. A complete list of country codes is contained in the Federal Information Processing Standards (FIPS) Publication 10-2, "Countries, Dependencies, and Areas of Special Sovereignty", dated 1976; a complete list of state codes is contained in the Federal Information Processing Standards (FIPS) Publication 5-1, "States and Outlying areas of the United States," dated 1970; and a complete list of city and place codes is contained in the Federal Information Processing Standards (FIPS) Publication 55, "Codes for Named Populated Places and Related Entities of the States of the United States," dated 1978.

\section{GENERAL DESCRIPTION:}

The NAWDEX Program Office assigns the liaison office code which is used to retrieve addresses of liaison offices from the WDSD database. The code for an office is unique within an organization but is not necessarily unique across the database. 
FIELD NAME:

IN DATABASE FILE:

MANDATORY:

DATA TYPE:

LARGEST OR LONGEST VALUE:
LTITLE

WDMLO

No

Character

40 characters

\section{DATA VALUES:}

This field contains up to $\mathbf{4 0}$ characters.

\section{GENERAL DESCRIPTION:}

This field contains the official name of the office in which the liaison official occupies, the title of the liaison official, or a combination of these, as appropriate. 
FIELD NAME:

IN DATABASE FILE:

MANDATORY:

DATA TYPE:

LARGEST OR LONGEST VALUE:

DATA VALUES:

The name of the office contains up to 40 characters.

GENERAL DESCRIPTION:

This field contains the official name of the office within the organization in which the liaison official occupies.
LAME

WDMLO

No

Character

40 characters 
FIELD NAME:

IN DATABASE FILE:

MANDATORY:

DATA TYPE:

LARGEST OR LONGEST VALUES: $\quad 40$ characters
LCONTAC

WDMLO

No

Character

\section{DATA VALUES:}

This field contains up to $\mathbf{4 0}$ characters.

\section{GENERAL DESCRIPTION:}

The contact is the name of the person within the organization to contact on matters related to water-data acquisition, coordination, and indexing, or other matters as defined by the LDIR field. 
FIELD NAME:

IN DATABASE FILE:

MANDATORY:

DATA TYPE:

LARGEST OR LONGEST VALUE:

DATA VALUES:

This field contains up to $\mathbf{4 0}$ characters.

GENERAL DESCRIPTION:

This field contains the street address or post office box number of the office of the liaison official.

\section{LSTREET}

WDMLO

No

Character

40 characters 
FIELD NAME:

IN DATABASE FILE:

MANDATORY:

DATA TYPE:

LARGEST OR LONGEST VALUE: 30 characters

DATA VALUES:

This field contains up to $\mathbf{3 0}$ characters.

GENERAL DESCRIPTION:

This field contains the city in which the liaison office is located. The city name accompanies the address (the LSTREET field) and, therefore, should be the name of the city used for mailing.
LAITY

WDMLO

No

Character 
FIELD NAME:

IN DATABASE FILE:

MANDATORY:

DATA TYPE:

LARGEST OR LONGEST VALUE: WY

\section{LSTATEA}

WDMLO

No

Character

\section{DATA VALUES:}

This field contains a postal code abbreviation that identifies the state in which the liaison office is located.

\section{GENERAL DESCRIPTION:}

Postal codes are alphabetic state abbreviations recognized by the U.S. Postal Service as part of a mailing address. The LSTATEA field has a value only if the office is located within the United States or one of its territories. If the office is outside the United States, this field has no value. 
FIELD NAME:

LZIP

IN DATABASE FILE:

WDMLO

MANDATORY:

No

DATA TYPE:

Character

LARGEST OR LONGEST VALUE:

9999999999

DATA VALUES:

This field contains up to ten digits and/or characters which is the U.S. Postal ZIP code or foreign postal code of the organization.

\section{GENERAL DESCRIPTION:}

The ZIP code is a geographic code that identifies areas within the United States and its possessions for simplifying the distribution of mail by the U.S. Postal Service. The ZIP code alinements do not adhere to boundaries of cities, counties, states, or other jurisdictions. For organizations outside the United States and its territories, the foreign postal code, if applicable, is formatted according to its local usage. 
FIELD NAME:

IN DATABASE FILE:

MANDATORY:

DATA TYPE:

LARGEST OR LONGEST VALUE: 30 characters
WDMLO

No

Character

DATA VALUES:

This field contains the name of the country in which the liaison office is located. If the office is in the United States, use "USA" as an abbreviation. For non-United States countries, store the full name of the country in this field.

\section{GENERAL DESCRIPTION:}

The name of the country applies to the country in which the office is physically located. It is the name that is part of the mailing address on correspondence addressed to the office. 
FIELD NAME:

IN DATABASE FILE:

MANDATORY:

DATA TYPE:

LARGEST OR LONGEST VALUE:
LPHONE

WDMLO

No

Character

999-999-9999

\section{DATA VALUES:}

This field contains the telephone number of the liaison office. If the office is within the United States or one of its territories, the number consists of a three-digit area code, followed by a dash, followed by the seven digits of the local telephone number. A dash appears between the third and fourth digits of the local number. If the office is outside the United States, format as required.

\section{GENERAL DESCRIPTION:}

This is the telephone number to call the liaison official. 
FIELD NAME:

IN DATABASE FILE:

MANDATORY:

DATA TYPE:

LARGEST OR LONGEST VALUE: 10 characters
WDMLO

Yes

Character

DATA VALUES:

Code Meaning

L Directory of Liaison Officials

I Directory of Indexing Officials

$\mathrm{N} \quad$ Directory of Water-Use Liaison Officials

\section{GENERAL DESCRIPTION:}

The LDIR field contains a combination of 1 to 10 codes, left-justified, used in retrieving specified types of directories. Each code may occur only once in this field. The NAWDEX Program Office will add codes, as the need arises, to meet future directory needs. 
DATABASE FILE NAME:

DATABASE FILE DEFINITION:

FIELDS:

\section{WDLSTAT}

Information about the geographic areas in which the liaison officials identified in the LCONTAC field has jurisdiction

NWDX_AGCY

LCODE

LSTATE 
FIELD NAME:

NWDX_AGCY

IN DATABASE FILE:

WDLSTAT (Also in WDORG)

MANDATORY:

Yes

DATA TYPE:

Character

LARGEST OR LONGEST VALUE: 5 characters

DATA VALUES:

The NAWDEX agency code varies in length from three to five characters. For federal organizations, it is US followed by a two- or three-character abbreviation of the organization's name. Values for non-federal organizations whose activities are within a given state boundary have a two-character state code followed by a NAWDEX-assigned sequence number. Values for non-federal organizations having activities at the multistate or national level have a three-to five-character abbreviation of the organization name (the characters US will not appear in the first two character positions). Alphabetic state codes are contained in the Federal Information Processing Standards (FIPS) Publication 5-1, dated June 15, 1970, "States and Outlying Areas of the United States." NAWDEX agency codes are presented in the publication, "Identification Codes for Organizations Listed in Computerized Data Systems of the U.S. Geological Survey" which may be obtained from the National Water Data Exchange, U.S. Geological Survey, 421 National Center, Reston, Virginia 22092. Telephone: (703) 648-6848; FTS 959-6848.

\section{GENERAL DESCRIPTION:}

The NAWDEX agency code is assigned by the NAWDEX Program Office and is the unique identifier for participating federal and non-federal organizations that actively collect and store water data. Non-federal organizations include state, county, and municipal agencies, as well as intergovernmental compacts, private organizations, universities, and any local organizations at other than county or municipal level. 
FIELD NAME:

IN DATABASE FILE:

MANDATORY:

DATA TYPE:

LARGEST OR LONGEST VALUE:
LCODE

WDLSTAT (Also in WDMLO)

Yes

Character

9 characters

\section{DATA VALUES:}

The NAWDEX Program Office assigns the liaison office code which consists of a 9character code. The first two characters of the code consists of two digits representing the state or two letters representing the country in which the office is located; the next five characters consist of five digits representing the city or place in which the office is located; and the next two characters consist of an arbitrary two-digit sequence number to uniquely identify multiple offices within the same city or place. A complete list of country codes is contained in the Federal Information Processing Standards (FIPS) Publication 10-2, "Countries, Dependencies, and Areas of Special Sovereignty", dated 1976; a complete list of state codes is contained in the Federal Information Processing Standards (FIPS) Publication 5-1, "States and Outlying areas of the United States," dated 1970; and a complete list of city and place codes is contained in the Federal Information Processing Standards (FIPS) Publication 55, "Codes for Named Populated Places and Related Entities of the States of the United States," dated 1978.

\section{GENERAL DESCRIPTION:}

The NAWDEX Program Office assigns the liaison office code used to retrieve addresses of liaison offices from the WDSD database. The code for an office is unique within an organization but is not necessarily unique across the database. 
FIELD NAME:

IN DATABASE FILE:

MANDATORY:

DATA TYPE:

LARGEST OR LONGEST VALUE:

\section{LSTATE}

WDLSTAT

Yes

Numeric

\section{DATA VALUES:}

This field contains a code representing a state within which the liaison official identified in the LCONTAC field has jurisdiction.

\section{GENERAL DESCRIPTION:}

State codes are contained in the Federal Information Processing Standards (FIPS) Publication 5-1, "States and Outlying Areas of the United States," dated June 15, 1970. 
DATABASE FILE NAME:

DATABASE FILE DEFINITION:

FIELDS:
WDLNUS

Information about the geographic areas in which the liaison official identified in the LCONTAC field has jurisdiction

NWDX_AGCY

LCODE

LNUS_CNTRY 
FIELD NAME:

IN DATABASE FILE:

MANDATORY:

DATA TYPE:

LARGEST OR LONGEST VALUE: 5 characters
NWDX_AGCY

WDLNUS (Also in WDORG)

Yes

Character

\section{DATA VALUES:}

The NAWDEX agency code varies in length from three to five characters. For federal organizations, it is US followed by a two-or three-character abbreviation of the organization's name. Values for non-federal organizations whose activities are within a given state boundary have a two-character state code followed by a NAWDEX-assigned sequence number. Values for non-federal organizations having activities at the multistate or national level have a three-to five-character abbreviation of the organization name (the characters US will not appear in the first two character positions). Alphabetic state codes are contained in the Federal Information Processing Standards (FIPS) Publication 5-1, dated June 15, 1970, "States and Outlying Areas of the United States." NAWDEX agency codes are presented in the publication, "Identification Codes for Organizations Listed in Computerized Data Systems of the U.S. Geological Survey" which may be obtained from the National Water Data Exchange, U.S. Geological Survey, 421 National Center, Reston, Virginia 22092. Telephone: (703) 648-6848; FTS 959-6848.

\section{GENERAL DESCRIPTION:}

The NAWDEX agency code is assigned by the NAWDEX Program Office and is the unique identifier for participating federal and non-federal organizations that actively collect and store water data. Non-federal organizations include state, county, and municipal agencies, as well as intergovernmental compacts, private organizations, universities, and any local organizations at other than county or municipal level. 
FIELD NAME:

IN DATABASE FILE:

MANDATORY:

DATA TYPE:

\section{LARGEST OR LONGEST VALUE:}

LCODE

WDLNUS (Also in WDMLO)

Yes

Character

9 characters

\section{DATA VALUES:}

The NAWDEX Program Office assigns the liaison office code which consists of a 9character code. The first two characters of the code consists of two digits representing the state or two letters representing the country in which the office is located; the next five characters consist of five digits representing the city or place in which the office is located; and the next two characters consist of an arbitrary two-digit sequence number to uniquely identify multiple offices within the same city or place. A complete list of country codes is contained in the Federal Information Processing Standards (FIPS) Publication 10-2, "Countries, Dependencies, and Areas of Special Sovereignty dated 1976; a complete list of state codes is contained in the Federal Information Processing Standards (FIPS) Publication 5-1, "States and Outlying areas of the United States," dated 1970; and a complete list of city and place codes is contained in the Federal Information Processing Standards (FIPS) Publication 55, "Codes for Named Populated Places and Related Entities of the States of the United States," dated 1978.

\section{GENERAL DESCRIPTION:}

The NAWDEX Program Office assigns the liaison office code used to retrieve addresses of liaison offices from the WDSD database. The code for an office is unique within an organization but is not necessarily unique across the database. 
FIELD NAME:

IN DATABASE FILE:

MANDATORY:

DATA TYPE:

LARGEST OR LONGEST VALUE: 2 characters
LNUS_CNTRY

WDLNUS

No

Character

DATA VALUES:

This field contains a code representing a country other than the United States within which the liaison official identified in the LCONTAC field, has jurisdiction.

\section{GENERAL DESCRIPTION:}

The liaison non-United States country code has a value only if the liaison official has jurisdiction outside the United States. Country codes are contained in the Federal Information Processing Standards (FIPS) Publication 10-2, "Countries, Dependencies, and Areas of Special Sovereignty," dated 1976. 
DATABASE FILE NAME:

DATABASE FILE DEFINITION:

FIELDS:
WDLCOM

General information about the liaison activities

NWDX_AGCY

LCODE

LCOM 
FIELD NAME:

IN DATABASE FILE:

MANDATORY:

DATA TYPE:

\section{LARGEST OR LONGEST VALUE: 5 characters}

NWDX_AGCY

WDLCOM (Also in WDORG)

Yes

Character

\section{DATA VALUES:}

The NAWDEX agency code varies in length from three to five characters. For federal organizations, it is US followed by a two- or three-character abbreviation of the organization's name. Values for non-federal organizations whose activities are within a given state boundary have a two-character state code followed by a NAWDEX-assigned sequence number. Values for non-federal organizations having activities at the multistate or national level have a three-to five-character abbreviation of the organization name (the characters US will not appear in the first two character positions). Alphabetic state codes are contained in the Federal Information Processing Standards (FIPS) Publication 5-1, dated June 15, 1970, "States and Outlying Areas of the United States." NAWDEX agency codes are presented in the publication, "Identification Codes for Organizations Listed in Computerized Data Systems of the U.S. Geological Survey" which may be obtained from the National Water Data Exchange, U.S. Geological Survey, 421 National Center, Reston, Virginia 22092. Telephone: (703) 648-6848; FTS 959-6848.

\section{GENERAL DESCRIPTION:}

The NAWDEX agency code is assigned by the NAWDEX Program Office and is the unique identifier for participating federal and non-federal organizations that actively collect and store water data. Non-federal organizations include state, county, and municipal agencies, as well as intergovernmental compacts, private organizations, universities, and any local organizations at other than county or municipal level. 
FIELD NAME:

IN DATABASE FILE:

MANDATORY:

DATA TYPE:

LARGEST OR LONGEST VALUE:
LCODE

WDLNUS (Also in WDMLO)

Yes

Character

9 characters

\section{DATA VALUES:}

The NAWDEX Program Office assigns the liaison office code which consists of a 9character code. The first two characters of the code consists of two digits representing the state or two letters representing the country in which the office is located; the next five characters consist of five digits representing the city or place in which the office is located; and the next two characters consist of an arbitrary two-digit sequence number to uniquely identify multiple offices within the same city or place. A complete list of country codes is contained in the Federal Information Processing Standards (FIPS) Publication 10-2, "Countries, Dependencies, and Areas of Special Sovereignty", dated 1976; a complete list of state codes is contained in the Federal Information Processing Standards (FIPS) Publication 5-1, "States and Outlying areas of the United States," dated 1970; and a complete list of city and place codes is contained in the Federal Information Processing Standards (FIPS) Publication 55, "Codes for Named Populated Places and Related Entities of the States of the United States," dated 1978.

\section{GENERAL DESCRIPTION:}

The NAWDEX Program Office assigns the liaison office code used to retrieve addresses of liaison offices from the WDSD database. The code for an office is unique within an organization but is not necessarily unique across the database. 
FIELD NAME:

IN DATABASE FILE:

MANDATORY:

DATA TYPE:

LARGEST OR LONGEST VALUE:
LCOM

WDLCOM

Yes

Character

40 characters

\section{DATA VALUES:}

This field contains comments about the liaison office and its data.

\section{GENERAL DESCRIPTION:}

The purpose of this field is to provide a means of storing information about a liaison office and its data holdings. The information may include anything that would potentially be of interest to a user of NAWDEX. 
DATABASE FILE NAME:

DATABASE FILE DEFINITION:

FIELDS:
WDMWDI

Information on the total number of an organization's data collection sites about which data are stored in the Master Water Data Index (MWDI) data base of the National Water Data Exchange (NAWDEX)

\author{
NWDX_AGCY \\ MNUS_CNTRY \\ MSTÄTE \\ MSW_QLTY \\ MSW-QNTY \\ MGW_QLTY \\ MGW_LVL \\ MGW-PUMP \\ MGLḠC \\ MWTR_USE \\ MMET_DAT \\ MDIR
}


FIELD NAME:

NWDX_AGCY

IN DATABASE FILE:

WDMWDI (Also in WDORG)

MANDATORY:

Yes

DATA TYPE:

Character

LARGEST OR LONGEST VALUE: 5 characters

DATA VALUES:

The NAWDEX agency code varies in length from three to five characters. For federal organizations, it is US followed by a two- or three-character abbreviation of the organization's name. Values for non-federal organizations whose activities are within a given state boundary have a two-character state code followed by a NAWDEX-assigned sequence number. Values for non-federal organizations having activities at the multistate or national level have a three-to five-character abbreviation of the organization name (the characters US will not appear in the first two character positions). Alphabetic state codes are contained in the Federal Information Processing Standards (FIPS) Publication 5-1, dated June 15, 1970, "States and Outlying Areas of the United States." NAWDEX agency codes are presented in the publication, "Identification Codes for Organizations Listed in Computerized Data Systems of the U.S. Geological Survey" which may be obtained from the National Water Data Exchange, U.S. Geological Survey, 421 National Center, Reston, Virginia 22092. Telephone: (703) 648-6848; FTS 959-6848.

\section{GENERAL DESCRIPTION:}

The NAWDEX agency code is assigned by the NAWDEX Program Office and is the unique identifier for participating federal and non-federal organizations that actively collect and store water data. Non-federal organizations include state, county, and municipal agencies, as well as intergovernmental compacts, private organizations, universities, and any local organizations at other than county or municipal level. 
FIELD NAME:

MNUS_CNTRY

IN DATABASE FILE:

WDMWDI

MANDATORY:

No

DATA TYPE:

Character

LARGEST OR LONGEST VALUES: 2 characters

DATA VALUES:

This field contains a country code if the organization has sites in the Master Water Data Index (MWDI) database that are physically located outside the United States. If the organization's sites are within the United States, this field is not valued. A complete list of country codes contained in the Federal Information Processing Standards (FIPS) Publication 10-2, "Countries, Dependencies, and Areas of Special Sovereignty," dated 1976.

\section{GENERAL DESCRIPTION:}

This field is valued only if the organization operates sites outside the boundaries of the United States and its territories and if one or more of those sites are indexed in the MWDI database. It bears no relationship to the location of the organization or to the organization's sites outside the United States that are not indexed in the MWDI. 
FIELD NAME:

MSTATE

IN DATABASE FILE:

WDMWDI

MANDATORY:

Yes

DATA TYPE:

Numeric

LARGEST OR LONGEST VALUES:

99

DATA VALUES:

This field contains a code representing a state or outlying area in which the organization operates sites, as long as one or more of those sites are indexed in the Master Water Data Index. A complete list of state and outlying area codes is contained in the Federal Information Processing Standards (FIPS) Publication, "States and Outlying Areas of the United States," dated June 15, 1970.

\section{GENERAL DESCRIPTION:}

The MSTATE field is valued for those states or outlying areas in which the organization operates sites that are indexed in the Master Water Data Index (MWDI). It bears no relationship to the location of the organization or to the organization's sites that are not indexed in the MWDI. 
FIELD NAME:

IN DATABASE FILE:

MANDATORY:

DATA TYPE:

LARGEST OR LONGEST VALUE:
MSW_QLTY

WDMWDI

No

Character

9999999

\section{DATA VALUES:}

This field contains the total number of surface-water-quality sites operated by the organization that are located in the state identified in the MSTATE field (or country identified in the MNUS_CNTRY field) and are indexed in the Master Water Data Index (MWDI). For the same organization and state/country, the value in the MSW_QLTY field must be less than or equal to the value in the SW_QLTY field.

\section{GENERAL DESCRIPTION:}

The purpose of this field is to provide information on the number of the organization's surface-water-quality sites that are indexed in the MWDI. It should not be confused with the SW_QLTY field, which is the total number of surface-water-quality sites operated by the organization, regardless of how many of them are indexed in the MWDI. If a site is indexed in the MWDI, detailed information about the site is available, including its name, location, period of record, and frequency of collection of the major surface-water-quality variables at the site. 
FIELD NAME:

IN DATABASE FILE:

MANDATORY:

DATA TYPE:

LARGEST OR LONGEST VALUE: 9999999
WDMWDI

No

Numeric

\section{DATA VALUES:}

This field contains the total number of surface-water-quantity sites operated by the organization that are located in the state identified in the MSTATE field (or country identified in the MNUS_CNTRY field) and are indexed in the Master Water Data Index (MWDI). For the same organization and state/country, the value in the MSW_QNTY field must be less than or equal to the value in the SW_QNTY field.

\section{GENERAL DESCRIPTION:}

The purpose of this field is to provide information on the number of the organization's surface-water-quantity sites that are indexed in the MWDI. It should not be confused with the SW_QNTY field, which is the total number of surface-water-quantity sites operated by the organization, regardless of how many of them are indexed in the MWDI. If a site is indexed in the MWDI, detailed information about the site is available, including its name, location, period of record, and frequency of collection of the major surface-waterquantity variables at the site. 
FIELD NAME:

MGW_QLTY

IN DATABASE FILE:

WDMWDI

MANDATORY:

No

DATA TYPE:

Numeric

LARGEST OR LONGEST KEY:

9999999

DATA VALUES:

This field contains the total number of ground-water-quality sites operated by the organization that are located in the state identified in the MSTATE field (or country identified in the MNUS_CNTRY field and are indexed in the Master Water Data Index. For the same organization and state/country, the value in the MGW_QLTY field must be less than or equal to the value in the GW_QLTY field.

\section{GENERAL DESCRIPTION:}

The purpose of this field is to provide information on the number of the organization's ground-water-quality sites that are indexed in the MWDI. It should not be confused with the GW_QLTY field, which is the total number of ground-water-quality sites operated by the organization, regardless of how many of them are indexed in the MWDI. If a site is indexed in the MWDI, detailed information about the site is available, including its name, location, period of record, and frequency of collection of the major ground-water-quality variables at the site. 
FIELD NAME:

MGW_LVL

IN DATABASE FILE:

WDMWDI

MANDATORY:

No

DATA TYPE:

Numeric

LARGEST OR LONGEST VALUE: 9999999

\section{DATA VALUES:}

This field contains the total number of ground-water-level sites operated by the organization that are located in the state identified in the MSTATE field (or country identified in the MNUS_CNTRY field) and are indexed in the Master Water Data Index (MWDI). For the same organization and state/country, the value in the MGW_LVL field must be less than or equal to the value in the GW_LVL field.

\section{GENERAL DESCRIPTION:}

The purpose of this field is to provide information on the organization's ground-water-level sites that are indexed in the MWDI. It should not be confused with the GW_LVL field, which is the total number of ground-water-level sites operated by the organization, regardless of how many of them are indexed in the MWDI. If a site is indexed in the MWDI, detailed information about the site is available, including its name, location, period of record, and frequency of collection of the ground-water levels at the site. 
FIELD NAME:

IN DATABASE FILE:

MANDATORY:

DATA TYPE:

LARGEST OR LONGEST VALUE:
MGW_PUMP

WDMWDI

No

Numeric

9999999

\section{DATA VALUES:}

This field contains the total number of ground-water-pumpage sites operated by the organization that are located in the state identified in the MSTATE field (or country identified in the MNUS_CNTRY field) and indexed in the Master Water Data Index (MWDI). For the same organization and state/country, the value in the MGW_PUMP the must be less than or equal to the value in the GW_PUMP field.

\section{GENERAL DESCRIPTION:}

The purpose of this field is to provide information on the number of the organization's ground-water-pumpage sites that are indexed in the MWDI. It should not be confused with the GW_PUMP field, which is the total number of ground-water-pumpage sites operated by the organization, regardless of how many of them are indexed in the MWDI. If a site is indexed in the MWDI, detailed information about the site is available, including its name, location, period of record, and frequency of collection of the ground-waterpumpage data at the site. 
FIELD NAME:

IN DATABASE FILE:

MANDATORY:

DATA TYPE:

LARGEST OR LONGEST VALUE:
MGLGC

WDMWDI

No

Numeric

9999999

\section{DATA VALUES:}

This field contains the total number of ground-water sites with geologic descriptions available, that are operated by the organization located in the state identified in the MSTATE field (or country identified in the MNUS_CNTRY field), and that are indexed in the Master Water Data Index (MWDI). For the same organization and state/country, the value in the MGLGC field must be less than or equal to the value in the GLGC field.

\section{GENERAL DESCRIPTION:}

The purpose of this field is to provide information on the number of the organization's ground-water sites that are indexed in the MWDI for which there is information describing the geology in which the sites are located. It should not be confused with GLGC, which is the total number of sites with geologic information operated by the organization, regardless of how many of them are indexed in the MWDI. If a site is indexed in the MWDI, detailed information about the site is available, including its name, location, period of record, and the geologic descriptors for the site. 
FIELD NAME:

IN DATABASE FILE:

MANDATORY:

DATA TYPE:

LARGEST OR LONGEST VALUE:
MWTR_USE

WDMWDI

No

Numeric

9999999

DATA VAlues:

Water-use data are not currently indexed in the Master Water Data Index. This field is, therefore, reserved for future use. 
FIELD NAME:

IN DATABASE FILE:

MANDATORY:

DATA TYPE:

LARGEST OR LONGEST VALUE:
MMET_DAT

WDMWDI

No

Numeric

9999999

\section{DATA VALUES:}

This field contains the total number of meteorological sites operated by the organization that are located in the state identified in the MSTATE field (or country identified in the MNUS_CNTRY field) and are indexed in the Master Water Data Index (MWDI). For the same organization and state/country, the value in the MMET_DAT field must be less than or equal to the value in the MET_DAT field.

\section{GENERAL DESCRIPTION:}

The purpose of this field is to provide information on the number of the organization's meteorological sites that are indexed in the MWDI. It should not be confused with the MET_DAT field, which is the total number of meteorological sites operated by the organization regardless of how many of them are indexed in the MWDI. If a site is indexed in the MWDI, detailed information about the site is available, including its name, location, period of record, and the frequency of collection of the major meteorological variables at the site. 
FIELD NAME:

IN DATABASE FILE:

MANDATORY:

DATA TYPE:

LARGEST OR LONGEST VALUE: 10 characters
MDIR

WDMWDI

Yes

Character

\section{DATA VALUES:}

Code Meaning

W Water Data Sources Directory

R Water-related Data Sources Directory

O Directory of Water Resources Organizations

\section{GENERAL DESCRIPTION:}

The MDIR field contains a combination of 1 to 10 codes, left-justified, used in retrieving specified types of directories. Each code may occur only once in this field. Additional codes will be added by the NAWDEX Program Office, as the need arises, to meet future directory needs. 
DATABASE FILE NAME:

DATABASE FILE DEFINITION:

FIELDS:
WDMCNTY

Identifies the counties in which the organization operates sites that are indexed in the Master Water Data Index

NWDX AGCY

MSTATE

MCNTY 
FIELD NAME:

IN DATABASE FILE:

MANDATORY:

DATA TYPE:

LARGEST OR LONGEST VALUE: 5 characters
NWDX_AGCY

WDMCNTY (Also in WDORG)

Yes

Character

\section{DATA VALUES:}

The NAWDEX agency code varies in length from three to five characters. For federal organizations, it is US followed by a two-or three-character abbreviation of the organization's name. Values for non-federal organizations whose activities are within a given state boundary have a two-character state code followed by a NAWDEX-assigned sequence number. Values for non-federal organizations having activities at the multistate or national level have a three-to five-character abbreviation of the organization name (the characters US will not appear in the first two character positions). Alphabetic state codes are contained in the Federal Information Processing Standards (FIPS) Publication 5-1, dated June 15, 1970, "States and Outlying Areas of the United States." NAWDEX agency codes are presented in the publication, "Identification Codes for Organizations Listed in Computerized Data Systems of the U.S. Geological Survey" which may be obtained from the National Water Data Exchange, U.S. Geological Survey, 421 National Center, Reston, Virginia 22092. Telephone: (703) 648-6848; FTS 959-6848.

\section{GENERAL DESCRIPTION:}

The NAWDEX agency code is assigned by the NAWDEX Program Office and is the unique identifier for participating federal and non-federal organizations that actively collect and store water data. Non-federal organizations include state, county, and municipal agencies, as well as intergovernmental compacts, private organizations, universities, and any local organizations at other than county or municipal level. 
FIELD NAME:

IN DATABASE FILE:

MANDATORY:

DATA TYPE:
MSTATE

WDMCNTY (Also in WDMWDI)

Yes

Numeric

99

\section{DATA VALUES:}

This field contains a code representing a state or outlying area in which the organization operates sites, as long as one or more of those sites are indexed in the Master Water Data Index. A complete list of state and outlying area codes is contained in the Federal Information Processing Standards (FIPS) Publication, "States and Outlying Areas of the United States," dated June 15, 1970.

\section{GENERAL DESCRIPTION:}

The MSTATE field is valued for those states or outlying areas in which the organization operates sites that are indexed in the Master Water Data Index (MWDI). It bears no relationship to the location of the organization or to the organization's sites that are not indexed in the MWDI. 
FIELD NAME:

IN DATABASE FILE:

MANDATORY:

DATA TYPE:

LARGEST OR LONGEST VALUE:
MCNTY

WDMCNTY (Also in WDMWDI)

Yes

Numeric

\section{DATA VALUES:}

This field contains a code for a county in which the organization operates one or more sites that are indexed in the Master Water Data Index. For sites operated outside the United States, there will be no occurrences in the WDMCNTY database file.

\section{GENERAL DESCRIPTION:}

This field is valued for those counties in which there are one or more data collection sites operated by the organization, if those sites are indexed in the MWDI. The counties must be in the state identified in the MSTATE field. A complete list of county codes is contained in the Federal Information Processing Standards (FIPS) publication 6-3, "Counties and County Equivalents of the States of the United States and the District of Columbia," dated December 15, 1979.

Note: Codes used to value this field include independent city codes for the States of Maryland, Missouri, Nevada, and Virginia; division codes for the State of Alaska; and county equivalents of Puerto Rico and the Virgin Islands. 
DATABASE FILE NAME:

DATABASE FILE DEFINITION:

FIELDS:
WDWRD

Information about water-related data that are collected and made available by the organization. Examples of water-related data include meteorological, water use, land use, oceanographic, and agricultural, demographic, and other types of data. Water related data are defined as any data having significance to users of water data or to those conducting waterresource projects or investigations.

NWDX_AGCY

PARAM CD

BEGIN YR

END_YR

NO_S̄ITES

NO-OBS

GEŌ AREA

OBS FREQ

STOR MEDIA

OTHR SRC

WRD_DIR 
FIELD NAME:

IN DATABASE FILE:

MANDATORY:

DATA TYPE:

LARGEST OR LONGEST VALUE:
NWDX_AGCY

WDWRD (Also in WDORG)

Yes

Character

5 characters

\section{DATA VALUES:}

The NAWDEX agency code varies in length from three to five characters. For federal organizations, it is US followed by a two-or three-character abbreviation of the organization's name. Values for non-federal organizations whose activities are within a given state boundary have a two-character state code followed by a NAWDEX-assigned sequence number. Values for non-federal organizations having activities at the multistate or national level have a three-to five-character abbreviation of the organization name (the characters US will not appear in the first two character positions). Alphabetic state codes are contained in the Federal Information Processing Standards (FIPS) Publication 5-1, dated June 15, 1970, "States and Outlying Areas of the United States." NAWDEX agency codes are presented in the publication, "Identification Codes for Organizations Listed in Computerized Data Systems of the U.S. Geological Survey" which may be obtained from the National Water Data Exchange, U.S. Geological Survey, 421 National Center, Reston, Virginia 22092. Telephone: (703) 648-6848; FTS 959-6848.

\section{GENERAL DESCRIPTION:}

The NAWDEX agency code is assigned by the NAWDEX Program Office and is the unique identifier for participating federal and non-federal organizations that actively collect and store water data. Non-federal organizations include state, county, and municipal agencies, as well as intergovernmental compacts, private organizations, universities, and any local organizations at other than county or municipal level. 
FIELD NAME:

IN DATABASE FILE:

MANDATORY:

DATA TYPE:

LARGEST OR LONGEST VALUE:
PARAM_CD

WDWRD

No

Character

99999999

\section{DATA VALUES:}

This field contains a code which identifies the type of water-related data available.

\section{GENERAL DESCRIPTION:}

The purpose of this field is to identify the individual types of water-related data that may be available from the organization. A different parameter code is assigned to each major category or subcategory of water-related data identified. A complete list of all codes assigned may be obtained from: National Water Data Exchange, U.S. Geological Survey, 421 National Center, Reston, Virginia 22092. 
FIELD NAME:

IN DATABASE FILE:

MANDATORY:

DATA TYPE:

LARGEST OR LONGEST VALUE: Current Year
BEGIN_YR

WDWRD

No

Character

\section{DATA VALUES:}

This field contains a four-digit value which identifies the year that the water-related data being reported were first collected by the organization.

\section{GENERAL DESCRIPTION:}

This field identifies the calendar year in which the organization first began to collect the water-related data that are being made available. 
FIELD NAME:

END_YR

IN DATABASE FILE:

WDWRD

MANDATORY:

No

DATA TYPE:

Character

LARGEST OR LONGEST VALUE: Current Year

DATA VALUES:

This field contains a four-digit value which identifies the year that data-collection activities for the water-related data being reported were ceased. If the organization is currently collecting the water-related data reported, this field is not valued.

\section{GENERAL DESCRIPTION:}

This field identifies the calendar year in which the organization discontinued collection of the water-related data being reported. If, at a future date, the collection of the waterrelated data is resumed, the former end date is deleted. 
FIELD NAME:

IN DATABASE FILE:

MANDATORY:

DATA TYPE:

LARGEST OR LONGEST VALUE
NO_SITES

WDWRD

No

Numeric

9999999

\section{DATA VALUES:}

This field contains the total number of sites, if applicable, at which the reported waterrelated data are, or have been, collected by the organization.

\section{GENERAL DESCRIPTION:}

The purpose of this field is to provide information on the number of sites at which the organization has the reported water-related data available. Some types of waterrelated data are collected on an areal or nonpoint source basis. In these cases, this field will not be valued. 
FIELD NAME:

NO_OBS

IN DATABASE FILE:

WDWRD

MANDATORY:

No

DATA TYPE:

Numeric

LARGEST OR LONGEST VALUE: 99999999

DATA VALUES:

This is the total number of occurrences or observations, if applicable, for which the reported water-related data are, or have been, collected and are available.

\section{GENERAL DESCRIPTION:}

Many types of water-related data are collected on an areal basis and the number-ofsites field is not applicable. The number of occurrences or observations of these data may, then, be reported to indicate the volume of data available to the user. 
FIELD NAME:

GEO_AREA

IN DATABASE FILE:

WDWRD

MANDATORY:

No

DATA TYPE:

Character

LARGEST OR LONGEST VALUE: S

DATA VALUES:

This field contains a code that describes the geographic area encompassed by the waterrelated data reported and available.

\section{GENERAL DESCRIPTION:}

Code Meaning

A Multicounty - Two or more counties, all in the same state, but not encompassing the entire state.

C One County - All the data available are for a single county.

Multicountry (International) - Data from more than one country are available.

M

Multistate (Province) - Data from more than one state or province are available, and all data are for a single country.

$N$

Nationwide - The available data span an entire country and are limited to that single country.

S

Statewide - The available data span an entire state or province and are limited to that single state or province. 
FIELD NAME:

OBS_FREQ

IN DATABASE FILE:

WDWRD

MANDATORY:

No

DATA TYPE:

Character

LARGEST OR LONGEST VALUE: $\quad Z$

\section{DATA VALUES:}

This field contains a code that best describes the frequency at which the water-related data reported are collected or measured.

\section{GENERAL DESCRIPTION:}

Code Frequency
A
Annual (Once per year)
B Other periodic (Less than once per year)
C Continuous, Year-round - Nonrecorder
D Continuous, Seasonal - Nonrecorder
E Eliminated Activity - Data are no longer being collected
1 Continuous, Year-round, Recorder used
J Continuous, Seasonal, Recorder used
M Monthly, Year-round
N Monthly, Seasonal
O Daily, Year-round
P Daily, Seasonal
Q Quarterly, Year-round.
R Quarterly, Seasonal
S Semiannual (Twice per year)
$U \quad$ Unique (One-time only) measurement
W Weekly, Year-round
$X \quad$ Weekly, Seasonal
Y Seasonal (No time period specified)
Z Data collected at an irregular or unspecified frequency 
FIELD NAME:

IN DATABASE FILE:

MANDATORY:

DATA TYPE:

\section{LARGEST OR LONGEST VALUE:}

STOR_MEDIA

WDWRD

No

Character

\section{DATA VALUES:}

This field contains a code that describes the type(s) of media used to store the waterrelated data reported.

\section{GENERAL DESCRIPTION:}

Code Meaning

C Computer recognizable - The data are stored on media that can be read by a computer. This might be punched cards, paper tape, magnetic tape, magnetic disk, drum, or some similar device.

D Computer and published - Data are stored in both computer recognizable and published form.

E Computer and microform - Data are stored in both computer recognizable and microform formats.

F Computer, published, and microform - Data are stored in computer recognizable, published, and microform formats.

G Published and microform - Data are stored in both published and microform formats.

M Microform - Printed data which are stored in reduced size on roll microfilm, microfiche, aperture cards, or some other type of microfilm.

P Published - The data are available in printed form. 
FIELD NAME:

IN DATABASE FILE:

MANDATORY:

DATA TYPE:

LARGEST OR LONGEST VALUE: 5 characters
OTHR_SRC

WDWRD

No

Character

\section{DATA VALUES:}

This is the NAWDEX Agency Code that identifies another organization that is a source of the organization's water-related data.

GENERAL DESCRIPTION:

A complete description of the NAWDEX Agency Code may be found in this dictionary under field NWDX_AGCY. This is the same code that is also stored in field OS_AGCY. If this field is valued, the WDOS database file must also be valued. 
FIELD NAME:

IN DATABASE FILE:

MANDATORY:

DATA TYPE:

LARGEST OR LONGEST VALUE: 10 characters
WRD_DIR

WDWRD

Yes

Character

DATA VALUES:

Code Meaning

W Water Data Sources Directory

R Water-related Data Sources Directory

O Directory of Water Resources Organizations

L D Directory of Liaison Officials

$1 \quad$ Directory of Indexing Officials

\section{GENERAL DESCRIPTION:}

The WRD_DIR field contains a combination of 1 to 10 codes, left-justifled, to be used in retrieving specified types of directories. Each code may occur only once in this field. Additional codes will be added by the NAWDEX Program Office, as the need arises, to meet future directory needs. 
DATABASE FILE NAME:

DATABASE FILE DEFINITION:

FIELDS:
WDPARAM

A cross reference of parameter codes and their names

PARAM_CD

PNAME 
FIELD NAME:

IN DATABASE FILE:

MANDATORY:

DATA TYPE:

LARGEST OR LONGEST VALUE:
PARAM_CD

WDPARAM (Also in WDWRD)

No

Character

99999999

\section{DATA VALUES:}

This field contains a code which identifies the type of water-related data available.

\section{GENERAL DESCRIPTION:}

The purpose of this field is to identify the individual types of water-related data that may be available from the organization. A different parameter code is assigned to each major category or subcategory of water-related data identified. A complete list of all codes assigned may be obtained from: National Water Data Exchange, U.S. Geological Survey, 421 National Center, Reston, Virginia 22092. 
FIELD NAME:

PNAME

IN DATABASE FILE:

WDPARAM

MANDATORY:

No

DATA TYPE:

Character

LARGEST OR LONGEST VALUE: 26 characters

DATA VALUES:

This field contains up to a 26-character description of a parameter code.

GENERAL DESCRIPTION:

Code Meaning

00010000

00010001

00010002

00010003

00010004

00010005

00010006

00010007

00010008

00010010

00010011

00010020

00010030

00020000

00020001

00020002

00020003

00020004

00020005

00020006

00020007

00020011

00020013

00021000

00100000

00100001

METEOROLOGICAL

PRECIPITATION

WIND MOVEMENT

AIR TEMPERATURE

PAN EVAPORATION

LAKE SURFACE EVAP

AIR QUALITY

AIR POLLUTANTS

EMISSIONS DATA

PRECIP EQUIVALENTS

SNOWFALL

RELATIVE HUMIDITY

CLIMATOLOGICAL DATA

WATER USE

WATER USE PUB SUP

WATER USE RURAL

WATER USED IRRIGATION

WATER USE INDUSTRIAL

WATER USED HYDRO PWR

STM ELEC PWR PLANT

WATER USE CEN PIVOT

RETURN FLOW MUNICIPAL

RETURN FLOW INDUSTRIAL

STATE STREAM USE CLASS

WATER RIGHTS

WATER RIGHTS PERMITS 


$\begin{array}{ll}00100010 & \text { SELF REPORTING DATA } \\ 00100012 & \text { WATER QUAL PERMIT } \\ 00100100 & \text { PUBLC WATER SUP (QUALITY } \\ 00109000 & \text { TOPOGRAPHIC DATA } \\ 00109001 & \text { CARTOGRAPHIC DATA } \\ 00109002 & \text { DIGITAL CARTO DATA } \\ 00109003 & \text { SATELLITE IMAGERY } \\ 00109010 & \text { FLOOD-PRONE AREA MAPS } \\ 00109015 & \text { GEOLOGIC MAPS } \\ 00109020 & \text { GEOPHYSICAL MAPS } \\ 00109025 & \text { HYDROLOGIC MAPS } \\ 00109030 & \text { LAND-USE MAPS } \\ 00109031 & \text { LAND COVER MAPS } \\ 00109035 & \text { MIN \& ENGY RES MAPS } \\ 00109040 & \text { NATIONAL ATLAS } \\ 00109045 & \text { RIVER SURVEY MAPS } \\ 00109050 & \text { SATELLITE IMAGE MAPS } \\ 00109055 & \text { TOPOGRAPHIC MAPS } \\ 00109060 & \text { WATER RESO DEV MAPS } \\ 00109300 & \text { AERIAL PHOTOGRAPHS } \\ 00109305 & \text { SPACE PHOTOGRAPHS } \\ 00200000 & \text { LAND USE } \\ 00201000 & \text { ABANDONED MINE INV } \\ 00202000 & \text { DAM INVENTORY } \\ 00300000 & \text { WELL REGISTRATION } \\ 00300001 & \text { WELL PERMITS } \\ 00300010 & \text { WELL LOGS } \\ 00300020 & \text { GEOLOGIC MAPPING } \\ 00300030 & \text { SPRINGS LOCS \& MEAS } \\ 00300040 & \text { GEOPHYSICAL DATA } \\ 00300050 & \text { EARTHQUAKE DATA } \\ 00301000 & \text { COAL DATA SYSTEM } \\ 00302000 & \text { GEOLOGIC DATA } \\ 00303000 & \text { HYDROGEOLOGIC DATA } \\ 00400000 & \text { OCEANOGRAPHIC DATA } \\ 00500000 & \text { HAZARD DATA } \\ 00500005 & \text { INDUST SOLID WASTE } \\ 00500010 & \text { HAZARDS WASTE DISP } \\ 00500020 & \text { HAZARDOUS SPILLS } \\ 00600000 & \text { CARTOGRAPHIC PRODUCTS } \\ 01000000 & \text { AGRICULTURAL DATA } \\ 01000005 & \text { SOIL MOISTURE } \\ 01000010 & \text { SOIL TYPES } \\ 01000020 & \text { SOIL SUM FILE } \\ & \end{array}$




$\begin{array}{ll}01000021 & \text { SOIL SURVEYS } \\ 01000022 & \text { SOIL MAPPING UNITS } \\ 01000023 & \text { SOIL INTERP MAPS } \\ 02000010 & \text { DEMOGRAPHIC DATA } \\ 02000011 & \text { SOCIODEMOGRAPHIC } \\ 02000020 & \text { HEALTH STATISTICS } \\ 02000021 & \text { EPIDEMIOLOGIC } \\ 02000030 & \text { ECONOMIC DATA } \\ 02000040 & \text { NAVIGATION DATA } \\ 02000050 & \text { MARINE DATA } \\ 10000001 & \text { WATER DISTRICT FILE }\end{array}$


DATABASE FILE NAME:

DATABASE FILE DEFINITION:

FIELDS:
WDSTATE

A cross reference of state codes and their names

\section{STATE}

STATEA

STATEB 
FIELD NAME:

IN DATABASE FILE:

MANDATORY:

DATA TYPE:

LARGEST OR LONGEST VALUE:
STATE

WDSTATE (Also in WDOSD and WDCNTY)

No

Numeric

99

\section{DATA VALUES:}

This field contains a code representing the state or outlying area in which the organization operates data collection sites. A complete list of state or outlying area codes is contained in the Federal Information Processing Standards (FIPS) Publication 5-1, "States and Outlying Areas of the United States," dated June 15, 1970.

\section{GENERAL DESCRIPTION:}

The STATE field is valued for those states or outlying area in which there are sites for which the organization has data. It bears no relationship to the location of the organization. 
FIELD NAME:

IN DATABASE FILE:

MANDATORY:

DATA TYPE:

LARGEST OR LONGEST VALUE:
STATEA

WDSTATE

No

Character

16 characters

DATA VALUES:

This field contains up to the first 16 characters of the name of the state or outlying area in which the organization operates data collection sites. A complete list of state or outlying area names is contained in the Federal Information Processing Standards (FIPS) Publication 5-1, "States and Outlying Areas of the United States," dated June 15, 1970.

GENERAL DESCRIPTION:

This field is valued for those states or outlying areas that have a value for the STATE field. 
FIELD NAME:

IN DATABASE FILE:

MANDATORY:

DATA TYPE:

LARGEST OR LONGEST VALUE: 14 characters
STATEB

WDSTATE

No

Character

\section{DATA VALUES:}

This field contains up to the last 14 characters of the name of the state or outlying area in which the organization operates data collection sites. A complete list of state or outlying area names is contained in the Federal Information Processing Standards (FIPS) Publication 5-1, "States and Outlying Areas of the United States," dated June 15, 1970.

\section{GENERAL DESCRIPTION:}

This field is valued for those states or outlying areas that have a value for the STATE field and the name is longer than 16 characters. 
DATABASE FILE NAME:

DATABASE FILE DEFINITION:

FIELDS:
WDCNTRY

A cross reference of country codes and their names

NUS_CNTRY

NUS_CNTRYA 
FIELD NAME:

IN DATABASE FILE:

MANDATORY:

DATA TYPE:

LARGEST OR LONGEST VALUE: 2 characters

No

Character
NUS_CNTRY

WDCNTRY (Also in WDOSD)

DATA VALUES:

This field contains a country code only if the organization operates data collection sites physically located outside the United States. If the organization's data collection sites are within the United States, the field is not valued. A complete list of country codes is contained in the Federal Information Processing Standards (FIPS) Publication 10-2, "Countries, Dependencies, and Areas of Special Sovereignty," dated 1976.

\section{GENERAL DESCRIPTION:}

The non-United States country code is valued for only those organizations that operate data collection sites that lie outside of the borders of the United States and its outlying areas. It bears no relationship to the location of the organization. 
FIELD NAME:

IN DATABASE FILE:

MANDATORY:

DATA TYPE:

LARGEST OR LONGEST VALUE: 16 characters
NUS_CNTRYA

WDCNTRY

No

Character

\section{DATA VALUES:}

This field contains up to 16 characters of the name of the country in which the organization operates data collection sites. A complete list of country names is contained in the Federal Information Processing Standards (FIPS) Publication 10-2, "Countries, Dependencies, and Areas of Special Sovereignty," dated 1976.

\section{GENERAL DESCRIPTION:}

This field is valued for those countries that have a value for the NUS_CNTRY field. 
DATABASE FILE NAME:

DATABASE FILE DEFINITION:

FIELDS:
WDDAT

A cross reference relating the NAWDEX agency, state numeric code, and the type of site

NWDX_AGCY

STATE

DAT 
FIELD NAME:

IN DATABASE FILE:

\section{MANDATORY:}

DATA TYPE:

LARGEST OR LONGEST VALUE: 5 characters
NWDX_AGCY

WDDAT (Also in WDORG)

Yes

Character

\section{DATA VALUES:}

The NAWDEX agency code varies in length from three to five characters. For federal organizations, it is US followed by a two- or three-character abbreviation of the organization's name. Values for non-federal organizations whose activities are within a given state boundary have a two-character state code followed by a NAWDEX-assigned sequence number. Values for non-federal organizations having activities at the multistate or national level have a three-to five-character abbreviation of the organization name (the characters US will not appear in the first two character positions). Alphabetic state codes are contained in the Federal Information Processing Standards (FIPS) Publication 5-1, dated June 15, 1970, "States and Outlying Areas of the United States." NAWDEX agency codes are presented in the publication, "Identification Codes for Organizations Listed in Computerized Data Systems of the U.S. Geological Survey" which may be obtained from the National Water Data Exchange, U.S. Geological Survey, 421 National Center, Reston, Virginia 22092. Telephone: (703) 648-6848; FTS 959-6848.

\section{GENERAL DESCRIPTION:}

The NAWDEX agency code is assigned by the NAWDEX Program Office and is the unique identifier for participating federal and non-federal organizations that actively collect and store water data. Non-federal organizations include state, county, and municipal agencies, as well as intergovernmental compacts, private organizations, universities, and any local organizations at other than county or municipal level. 
FIELD NAME:

IN DATABASE FILE:

MANDATORY:

DATA TYPE:

LARGEST OR LONGEST VALUE:
STATE

WDDAT (Also in WDOSD and WDCNTY)

No

Numeric

99

\section{DATA VALUES:}

This field contains a code representing the state or outlying area in which the organization operates data collection sites. A complete list of state or outlying area codes is contained in the Federal Information Processing Standards (FIPS) Publication 5-1, "States and Outlying Areas of the United States," dated June 15, 1970.

\section{GENERAL DESCRIPTION:}

The STATE field is valued for those states or outlying area in which there are sites for which the organization has data. It bears no relationship to the location of the organization. 
FIELD NAME:

DAT

IN DATABASE FILE:

WDDAT

MANDATORY:

No

DATA TYPE:

Character

LARGEST OR LONGEST VALUE:

11111

DATA VALUES:

This field contains 5 digits with each digit valued as "0" or "1".

GENERAL DESCRIPTION:

WDDAT is created as necessary by the program, WDMAIN. A "1" indicates information about the number and type of site operated by the organization exist. A " 0 " indicates no information exist. Position 1 of this field pertains to the SW_QNTY field or the MSW_QNTY field. Position 2 pertains to the SW_QLTY field or the MSW_QLTY field. Position 3 pertains to the GW_QLTY field or the MGW_QLTY field. Position 4 pertains to the GW_LVL field or the MḠW_LVL field. Position 5 pertains to the GW_PUMP field or the MGW_PUMP field. 


\section{REFERENCES}

Burton, J. S., Morris, J. E., Green, J. W., and Dolnack, D. J., 1991, Improved service of the U.S. Geological Survey's National Water Data Exchange (NAWDEX) Program, in Second International Symposium on Advanced Technology in Natural Resources Management, Washington, D.C., November 12-15, 1990, Proceedings: Resource Technology 90, p. 186-205.

Edwards, M. D., and Josefson, B. M., 1982, Identification codes for organizations listed in computerized data systems of the U.S. Geological Survey: U.S. Geological Survey Open-File Report 82-921, 114 p.

Edwards, M. D., 1982, Definitions of the components of the Water Data Sources Directory maintained by the National Water Data Exchange: U.S. Geological Survey OpenFile Report 82-923, $121 \mathrm{p}$.

U.S. Department of Commerce, National Bureau of Standards, 1970, States and outlying areas of the United States: Federal Information Processing Standards (FIPS) Publication 5-1, $4 \mathrm{p}$.

1976, Countries, dependencies, and areas of special sovereignty: Federal Information Processing Standards (FIPS) Publication 10-2, 25 p.

1978, Codes for named populated places and related entities of the States of the United States, Volumes 1 and 2: Federal Information Processing Standards (FIPS) Publication 55, 1,946 p.

1979 , Counties and county equivalents of the States of the United States and the District of Columbia: Federal Information Processing Standards (FIPS) Publication 6-3, $35 \mathrm{p}$. 


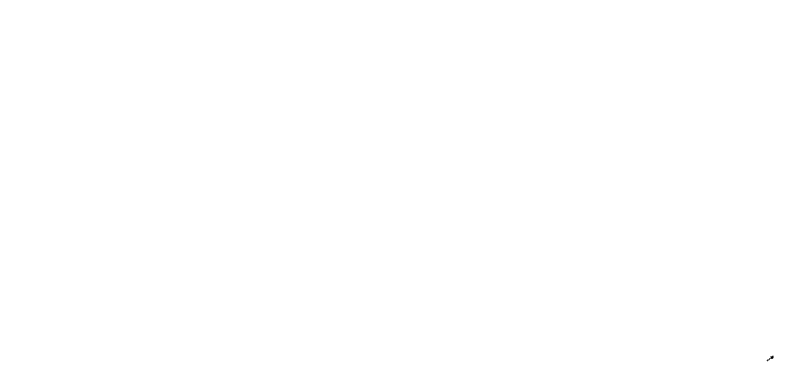

